Estudios Constitucionales, Año 10, No 2, 2012, pp. 643 - 682.

ISSN 0718-0195

Centro de Estudios Constitucionales de Chile Universidad de Talca

"Inconstitucionalidad de la denuncia de la Convención Americana sobre

Derechos Humanos por Venezuela"

Carlos Ayala Corao

\title{
INCONSTITUCIONALIDAD DE LA DENUNCIA DE LA CONVENCIÓN AMERICANA SOBRE DERECHOS HUMANOS POR VENEZUELA
}

\author{
Carlos Ayala Corao ${ }^{1}$ \\ Profesor de Derecho Constitucional \\ cayala@cjlegal.net
}

SUMARIO: Introducción. I. La violación de la jerarquia y supremacía de la constitución (artículos 23, 333 y 339). 1. La violación del bloque de la constitucionalidad. 2. La violación de la supremacía constitucional. A. La violación expresa del artículo 339 de la Constitución. II. La violación del derecho de petición internacional consagrado en el articulo 31 de la Constitución. III. La violación del principio de la progresividad de los derechos humanos consagrado en el artículo 19 de la Constitución. IV. Conclusión y acciones.

\section{INTRODUCCIÓN}

Mediante la nota oficial diplomática identificada con el número 000125 emanada del Ministro del Poder Popular para las Relaciones Exteriores de la República Bolivariana de Venezuela, Nicolás Maduro Moros, de fecha 6 de septiembre de 2012 adoptada por órdenes e instrucciones directas del Presidente de la República Bolivariana de Venezuela, Hugo Chávez Frías, fue presentada el 10 de septiembre de 2012 ante la Secretaría General de la Organización de Estados Americanos ("OEA"), la denuncia de la Convención Americana sobre Derechos Humanos (“CADH”).

De conformidad con la CADH, los Estados partes podrán denunciar este instrumento, mediante un preaviso de un año, notificando al Secretario General de la OEA, quien debe informar a las otras partes ${ }^{2}$; pero, en todo caso, la denuncia de la $\mathrm{CADH}$ no tiene por efecto desligar al Estado parte interesado

\footnotetext{
${ }^{1}$ El autor es profesor de Derecho Constitucional en la Facultad de Derecho de la Universidad Central de Venezuela en Caracas y de la Facultad de Derecho de la Universidad Católica de Caracas. Ex Presidente de la Comisión Interamericana de Derechos Humanos. Miembro de la Comisión Internacional de Juristas.

${ }^{2}$ Artículo 78, Convención Americana sobre Derechos Humanos (“CADH”).
} 
de las obligaciones contenidas en esa Convención en lo que concierne a todo hecho que, pudiendo constituir una violación de esas obligaciones, haya sido cumplido por él con anterioridad a la fecha en la cual la denuncia produce efecto $^{3}$.

Si bien la denuncia de los tratados en general podría considerarse, un acto de gobierno ordinario en las relaciones internacionales, la misma está sujeta a determinadas limitaciones y exclusiones conforme al derecho constitucional y el derecho internacional. En efecto, en términos generales, la denuncia de un tratado es un acto dictado en ejecución directa e inmediata de la Constitución, toda vez que la "política y la actuación internacional de la República" es una competencia del Poder Público Nacional”“4. En este sentido, el Presidente de la República como Jefe de Estado, ${ }^{5}$ tiene la atribución constitucional general para "celebrar y ratificar los tratados, convenios o

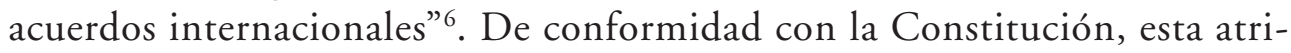
bución del Presidente de la República ${ }^{7}$ requiere para su validez del refrendo del Ministro de Relaciones Exteriores, quien en el presente caso, en ejecución -inconstitucional- de dicha norma constitucional, procedió a presentar la denuncia de la CADH.

En este sentido, es un hecho público y notorio, que la decisión de denunciar la CADH fue incluso anunciada por el Presidente Hugo Rafael Chávez Fría, en una alocución nacional en cadena de radio y televisión en fecha 24 de julio de $2012^{8}$. Por lo cual, la ejecución de dicha denuncia le correspondió realizarla al Ministro del Poder Popular para las Relaciones Exteriores, como "órgano directo del Presidente de la República" y en definitiva como órgano competente para realizar actos de esa naturaleza ${ }^{10}$.

\footnotetext{
3 Artículo 78.2, CADH.

${ }^{4}$ Artículo 156 numeral 1, Constitución de la República Bolivariana de Venezuela ("CRBV”).

${ }^{5}$ Artículo 226, CRBV.

${ }^{6}$ Artículo 236 numeral 4, CRBV.

7 Artículo 236, CRBV.

${ }^{8}$ Disponible en: http://www.youtube.com/watch?v=q6_6NgfyxJQ; http://www.youtube.com/ watch?v=FxJY4ghM1-w

${ }^{9}$ Artículo 242, CRBV.

${ }^{10}$ Artículo 8 del Decreto sobre Organización y Funcionamiento de la Administración Pública Nacional, publicado en la Gaceta Oficial (“G.O.”) No 39.202 de 17 de junio de 2009; y artículo 14 del
} 
De esta manera, por disposición del Presidente de la República Bolivariana de Venezuela, Hugo Chávez Frías, el Ministro del Poder Popular para las Relaciones Exteriores, Nicolás Maduro Moros, procedió a denunciar la $\mathrm{CADH}$ mediante la nota oficial diplomática identificada con el número 000125 emanada de su Despacho, de fecha 6 de septiembre de 2012, en la cual, luego de unas consideraciones impertinentes concluyó informando al Secretario General de la OEA ${ }^{11}$ :

Por lo anterior, en nombre de mi Gobierno, me permito manifestar la decisión soberana de la República Bolivariana de Venezuela de denunciar la Convención Americana sobre Derechos Humanos, razón por la cual, a tenor de lo dispuesto en su artículo 78, mucho apreciaré considere la presente nota como la Notificación de Denuncia, para que, a partir del término establecido en la misma, cesen sus efectos internacionales, en cuanto a ella se refiere, y la competencia de sus órganos para nuestro país, tanto de la Comisión Interamericana de Derechos Humanos como de la Corte Interamericana de Derechos Humanos.

De esta forma, la denuncia de la CADH ordenada por el Presidente de la República y ejecutada mediante la nota oficial diplomática identificada con el número 000125 emanada del Despacho del Ministro de Relaciones Exteriores de fecha 6 de septiembre de 2012, fue efectivamente materializada en fecha 10 de septiembre de 2012, como se evidencia del Comunicado de Prensa del Secretario General de la OEA de esa fecha. En este Comunicado de Prensa el Secretario General de la OEA expresó que "[e]n el día de hoy, el gobierno de la República Bolivariana de Venezuela comunicó al Secretario General de la Organización de los Estados Americanos, José Miguel Insulza, mediante nota oficial, que denuncia la Convención Americana sobre Derechos Humanos". El Secretario General de la OEA finalizó su Comunicado, lamentando "la decisión adoptada por el gobierno de la República Bolivariana de Venezuela, de denunciar este instrumento jurídico, uno de los pilares de la normativa legal que ampara la defensa de los derechos humanos en el continente"12.

Reglamento Orgánico del Ministerio del Poder Popular para Relaciones Exteriores, publicado en la G.O. No 39.841 de 12 de enero de 2012.

${ }^{11}$ Ministerio del Poder Popular para Relaciones Exteriores de la República Bolivariana de Venezuela. Nota Oficial Diplomática No 000125 de fecha 6 de septiembre de 2012.

12 OEA, Secretario General de la OEA comunica denuncia de la Convención Americana sobre Derechos Humanos de parte de Venezuela, Comunicado C-307/12, 10 de septiembre de 2012, disponible en: http:// www.oas.org/es/centro_noticias/comunicado_prensa.asp?sCodigo=C-307/12 
De conformidad con la propia $\mathrm{CADH}$, una vez transcurrido un año de este preaviso es que la denuncia entrará en vigor; y por ser precisamente un tratado de protección colectiva, esta notificación al Secretario General de la Organización, debe ser informada por él a los demás Estados partes de dicho instrumento ${ }^{13}$. Por lo cual, la denuncia presentada se hará efectiva en fecha 10 de septiembre de 2013.

Ahora bien, ese acto mediante el cual el Gobierno de Venezuela procedió a denunciar la $\mathrm{CADH}$, en el derecho interno viola las normas y principios constitucionales relativos a: la jerarquía y supremacía constitucional de los tratados sobre derechos humanos, el derecho de petición internacional para el amparo de los derechos humanos, los requisitos y límites constitucionales de los estados de excepción, los derechos humanos como principio rector de las relaciones internacionales del Estado venezolano y la progresividad de los derechos humanos, consagrados en los artículos 23, 333, 339, 31, 152 y 19, respectivamente, de la Constitución.

\section{LA VIOLACIÓN DE LA JERARQUÍA Y SUPREMACÍA DE LA CONSTITUCIÓN}

(ARTÍ́CULOS 23, 333 Y 339)

La Constitución de la República Bolivariana de Venezuela de 1999, consagró una norma singular, que establece la jerarquía constitucional de los tratados relativos a los derechos humanos:

Articulo 23. Los tratados, pactos y convenciones relativos a derechos humanos, suscritos y ratificados por Venezuela, tienen jerarquía constitucional y prevalecen en el orden interno, en la medida en que contengan normas sobre su goce y ejercicio más favorables a las establecidas en esta Constitución y en las leyes de la República, y son de aplicación inmediata y directa por los tribunales y demás órganos del Poder Público. (Resaltados y cursivas añadidos).

En consecuencia, en nuestro sistema constitucional, los tratados se equiparan con la misma jerarquía normativa de la Constitución. En otras palabras, los tratados internacionales tienen rango constitucional, por lo que adquieren la supremacía y en consecuencia la rigidez, propias de la Constitución ${ }^{14}$.

\footnotetext{
${ }^{13}$ Artículo 78.1, CADH.
}

${ }^{14}$ Ver nuestros trabajos sobre este tema en: Ayala CORAO, Carlos: "La jerarquía de los instrumentos internacionales sobre derechos humanos" en El nuevo Derecho Constitucional Latinoamericano, Volumen II, Konrad Adenauer Stiftung, CIEDLA Asociación Venezolana de Derechos Constitucional, Copre, 
La incorporación de la norma contenida en el artículo 23 de la Constitución de 1999 encuentra su fundamento además en la Base Comicial Octava para la convocatoria de la Asamblea Nacional Constituyente, que expresamente dispuso que:

Una vez instalada la Asamblea Nacional Constituyente, como poder originario que recoge la soberanía popular, deberá dictar sus propios estatutos de funcionamiento, teniendo como límites los valores y principios de nuestra historia republicana, así como el cumplimiento de los tratados internacionales, acuerdos y compromisos válidamente suscritos por la República, el carácter progresivo de los derechos fundamentales del hombre y las garantías democráticas dentro del más absoluto respeto de los compromisos asumidos. (Resaltados y cursivas añadidos).

Dicha base Comicial fue consultada y aprobada por el pueblo de Venezuela como depositario del poder constituyente originario, mediante el referéndum consultivo celebrado el 25 de abril de 1999, en el cual el 81,74\% de los electores aprobó la convocatoria a una Asamblea Nacional Constituyente conjuntamente con las Bases Comiciales propuestas por el Presidente de la República ${ }^{15}$. De allí, que, mediante dicha consulta popular se "aprobó la convocatoria a una Asamblea Nacional Constituyente que redactara una nueva Constitución y reorganizara los Poderes Públicos, actuando como prolongación del Poder Constituyente originario que le pertenece" ${ }^{16}$. Por lo cual, es evidente la voluntad popular inequívoca del poder constituyente originario del pueblo de Venezuela, expresado a través de la aprobación de dicha Base Comicial Octava, de instruir a la Asamblea Nacional Constituyente que se convocó mediante ese referendo, a fin de que elaborara una nueva Constitución que reflejara en

\footnotetext{
Caracas, 1996; "La jerarquía de los tratados de derechos humanos" en El futuro del sistema interamericano de protección de los Derechos Humanos. Instituto Interamericano de Derechos Humanos. San José de Costa Rica, 1998; La jerarquía constitucional de los tratados relativos a derechos humanos y sus consecuencias, Fundación Universitaria de Derecho, Administración y Política (Funda), México, 2004; y "Las consecuencias de la jerarquia Constitucional de los Tratados Relativos a Derechos Humanos" en Rumbos del Derecho Internacional de los Derechos Humanos, Estudios en Homenaje al Profesor Antonio Augusto Cancado Trindade, Tomo V, Porto Alegre, Brasil, 2005.

15 Los resultados oficiales del Consejo Nacional Electoral de dicho referendo pueden ser consultados en ESDATA, Referéndum Constituyente de 1999, disponible en: http://esdata.info/static/ constituyente_1999.

${ }^{16}$ Dirección de Archivos y Biblioteca de la Asamblea Nacional, República Bolivariana de Venezuela: El Poder Legislativo en la Historia, disponible en: http://www.monitorlegislativo.net/media/historiaAN. pdf).
} 
su contenido esencial los valores y principios de los tratados, acuerdos y compromisos sobre derechos humanos. Como consecuencia de ello, la Asamblea Nacional Constituyente elaboró y sancionó la Constitución de la República Bolivariana de Venezuela, la cual igualmente resultó aprobada por el pueblo mediante el referendo celebrado el 15 de diciembre de $1999^{17}$.

Debe afirmarse por tanto, que la jerarquía constitucional de los tratados sobre derechos humanos contenida en el artículo 23 de la Constitución de 1999 , encuentra su fundamento y respaldo en la voluntad manifestada por el pueblo electoral de Venezuela, quien en ejercicio de su poder constituyente originario, instruyó a la Asamblea Nacional Constituyente mediante la aprobación de la Base Comicial Octava, para que elaborara una nueva Constitución que reflejara en su contenido esencial los valores y principios de los tratados, acuerdos y compromisos sobre derechos humanos; lo cual fue así ejecutado por dicha Constituyente al sancionar el artículo 23 de la Constitución, la cual fue a su vez aprobada por el referendo popular.

La jerarquía constitucional de los tratados sobre derechos humanos representa una tendencia emergente en el constitucionalismo latinoamericano desde finales del siglo XX. En este sentido, tras los antecedentes de la Constitución Peruana de 1979, la nueva Constitución de Argentina resultante de la reforma de 1994, le otorgó jerarquía constitucional a los tratados y declaraciones vigentes sobre derechos humanos que enumera expresa y taxativamente; y los demás tratados sobre derechos humanos, podrán gozar de dicha jerarquía constitucional, en caso de que al ser aprobados por el Congreso se les imponga de esa jerarquía por el voto de las dos terceras partes de la totalidad de los miembros de cada Cámara ${ }^{18}$.

Siguiendo esta tendencia, posteriormente las constituciones de varios países latinoamericanos, incluida la de Venezuela de 1999, han otorgado a los tratados sobre derechos humanos jerarquía constitucional (ej. Brasil, República Dominicana y Ecuador).

En el caso de Venezuela, como vimos, a partir de la Constitución de 1999, todos los tratados, pactos y convenciones sobre derechos humanos adquirieron por

\footnotetext{
17 Sobre el proceso de convocatoria y funcionamiento de la Asamblea Nacional Constituyente de 1999 y la aprobación de la Constitución de ese mismo año, ver: BREWer-CARÍAs, Allan R.: Poder Constituyente Originario y Asamblea Nacional Constituyente. Caracas, 1999 y La Constitución de 1999. Comentada por Allan R. Brewer-Carias. Caracas, 2000.

${ }^{18}$ Artículo 75 inciso 22, Constitución de la Nación Argentina, Reforma de 1994.
} 
mandato expreso del artículo 23 la jerarquía constitucional. En el caso de la $\mathrm{CADH}$, habiendo sido ratificada por Venezuela en $1977^{19}$ y siendo una convención relativa a derechos humanos, adquirió la jerarquía constitucional desde el momento mismo de la entrada en vigencia de la Constitución ${ }^{20}$.

La incorporación de los tratados relativos a los derechos humanos en la Constitución, y particularmente el otorgamiento de la jerarquía constitucional a éstos, tiene -al menos- las siguientes consecuencias en el orden público constitucional venezolano, que en el presente caso evidencian los siguientes vicios de inconstitucionalidad del acto de denuncia de la CADH.

\section{La violación del bloque de la constitucionalidad}

La primera consecuencia de la jerarquía constitucional de los tratados relativos a derechos humanos es su incorporación al bloque de la constitución también conocido como el bloque de la constitucionalidad. Ello significa que en Venezuela los tratados sobre derechos humanos tienen en el derecho interno la misma jerarquía que la propia Constitución, por mandato expreso de la norma contenida en el citado artículo 23 constitucional. Pero incluso, por expresa disposición de esta misma norma, estos tratados incluso "prevalecen en el orden interno, en la medida en que contengan normas sobre su goce y ejercicio más favorables a las establecidas en esta Constitución”.

De allí que en las fuentes directas del Derecho Constitucional además de las normas constitucionales contenidas en el texto mismo de la Constitución, están igualmente incorporados en la misma categoría, rango y jerarquía, todos los tratados relativos a los derechos humanos que hayan sido ratificados por Venezuela, como es el caso de la CADH. Así, en los sistemas jurídicos como el venezolano, en los cuales los tratados relativos a los derechos humanos tienen jerarquía constitucional, el bloque de la constitucionalidad está integrado por el propio texto de la Constitución y por todos los tratados de derechos humanos ratificados por el Estado -y las decisiones de los órganos de estos

\footnotetext{
19 Ley Aprobatoria de la Convención Americana sobre Derechos Humanos publicada en la G.O. No 31.256 de 14-6-77, y la CADH fue ratificada internacionalmente mediante el depósito del instrumento en la Secretaría General de la OEA el 08-9-77. Ver: Convención Americana sobre Derechos Humanos: Signatarios y estado actual de las ratificaciones de la Convención Americana sobre Derechos Humanos en http://www.oas.org/es/cidh/mandato/Basicos/convratif.asp

${ }^{20}$ Cuando fue por primera vez publicada en la G.O. No 36.860 de 30 de diciembre de 1999.
} 
tratados-. Aparte de estos mecanismos, la cláusula de la descentralización ${ }^{21}$, autoriza a la transferencia de determinadas competencias constitucionales del Poder Nacional ${ }^{22}$ a los estados y municipios, dando lugar igualmente a leyes constitucionales que integran el bloque de la constitucionalidad ${ }^{23}$.

El concepto del bloque de la constitucionalidad fue introducido en Francia por el profesor Favoreu y la jurisprudencia del Consejo Constitucional Francés $^{24}$, para referirse a los instrumentos jurídicos que tienen el mismo valor y el rango constitucional, lo que equivale a estar contenidos en la propia jerarquía de la Constitución. Ese bloque de la constitucionalidad contiene en Francia los siguientes elementos esenciales: la Constitución de 1958, la Declaración de Derechos del Hombre y del Ciudadano de 1789, el Preámbulo de la Constitución de 1946, y los principios fundamentales reconocidos por las leyes de la República (elementos marginales). Sin embargo, en Francia las normas internacionales no forman parte del referido bloque de la constitucionalidad, a diferencia de Venezuela donde los tratados relativos a los derechos humanos sí integran expresamente el bloque de la constitucionalidad.

La consecuencia jurídica de que los tratados sobre derechos humanos tengan jerarquía constitucional y, por tanto, integren el bloque de la constitucionalidad es que al ser normas supremas, vinculan al resto del ordenamiento jurídico, el cual debe sujetarse a ellos al igual que a la propia Constitución. Por lo cual, al igual que la Constitución, los tratados sobre derechos humanos son "la norma suprema y el fundamento del ordenamiento jurídico" por lo que "todas las personas y los órganos que ejercen el Poder Público están sujetos" a ellos ${ }^{25}$. De allí que todo acto del poder público que viole o menoscabe los derechos garantizados en los tratados sobre derechos humanos es nulo; y los funcionarios públicos que lo ordenen o ejecuten incurren en responsabilidad penal, civil y administrativa, según los casos, sin que les sirvan de excusa órdenes superiores ${ }^{26}$.

\footnotetext{
${ }^{21}$ Artículo 157, CRBV.

22 Artículo 156, CRBV.

${ }^{23}$ Sobre el particular, Ayala Corao, Carlos: "Naturaleza y Alcance de la Descentralización Estatal" en Leyes para la Descentralización Politica de la Federación, Caracas, 1990.

${ }^{24}$ Favoreu, Louis y Rubio Llorente, Francisco: El bloque de la constitucionalidad, Universidad de Sevilla, Cuadernos Civitas, Madrid, 1991.

${ }^{25}$ Artículo 7, CRBV.

${ }^{26}$ Artículo 25, CRBV.
} 
En este sentido, todos los jueces, al estar obligados a asegurar la integridad de la Constitución, deben igualmente garantizar la integridad de los tratados relativos a derechos humanos ${ }^{27}$. Por lo que, en virtud de la obligación de todos los jueces de la República de asegurar la "integridad de la Constitución", en caso de incompatibilidad de una ley u otra norma jurídica con un tratado sobre derechos humanos, se aplicarán las disposiciones de dicho tratado, correspondiendo a los tribunales en cualquier causa, aun de oficio, decidir lo conducente ${ }^{28}$. Además, cuando una ley, un acto que tenga rango de ley u otro acto de los órganos que ejercen el poder público dictado en ejecución directa e inmediata de la Constitución colida con un tratado sobre derechos humanos, en ejercicio del control concentrado de la constitucionalidad, le corresponde declarar su nulidad a la Sala Constitucional del Tribunal Supremo de Justicia ${ }^{29}$. En consecuencia, el control concentrado de la constitucionalidad por la Sala Constitucional del Tribunal Supremo de Justicia, para declarar la nulidad de las leyes nacionales, estadales y municipales, de los actos de gobierno, de los decretos de estado de excepción, para revisar las sentencias definitivamente firmes, y para controlar la inconstitucionalidad por omisión legislativa, debe en definitiva ser ejercido conjuntamente con base en los tratados sobre derechos humanos en virtud de su jerarquía constitucional ${ }^{30}$.

Esta tesis es compartida por un sector importante en el derecho comparado, particularmente el latinoamericano, como es el caso de Costa Rica donde desde 1989 la jurisdicción constitucional tiene asignada la competencia de controlar la "conformidad del ordenamiento interno con el Derecho Internacional o Comunitario, mediante la acción de inconstitucionalidad y demás cuestiones de constitucionalidad" 31 .

En este sentido, la jurisprudencia constitucional latinoamericana ha desarrollado la incorporación de los tratados sobre derechos humanos al bloque de la constitucionalidad como consecuencia de la jerarquía constitucional de aquéllos.

La misma Sala Constitucional del Tribunal Supremo de Justicia de Venezuela (“TSJ"), ha aceptado la noción jurídica del bloque de la constitucionalidad, in-

\footnotetext{
${ }^{27}$ Artículo 334, encabezamiento, CRBV.

${ }_{28}$ Artículo 334, primer párrafo, CRBV.

${ }^{29}$ Artículo 334, segundo párrafo, CRBV.

30 Artículo 336, CRBV.

${ }^{31}$ Ley de la Jurisdicción Constitucional, República de Costa Rica, No 7135, de 11 de octubre de 1989.
} 
corporando con base al artículo 23, a los tratados sobre derechos humanos. Así, en el caso Harry Gutiérrez Benavides y otro, dicha Sala Constitucional citando varios instrumentos internacionales sobre derechos humanos, incluida la propia $\mathrm{CADH}$, afirmó que todos ellos son "integrantes" "del llamado bloque de la constitucionalidad de acuerdo con el artículo 23 del Texto Fundamental" 32 . Ese criterio fue reiterado un año más tarde por esa misma Sala Constitucional en el caso Esteban Gerbasi, al afirmar que los artículos 2o, 22 y 23 de la Constitución "se desprende que la interpretación constitucional debe siempre hacerse conforme al principio de preeminencia de los derechos humanos, el cual, junto con los pactos internacionales suscritos y ratificados por Venezuela relativos a la materia, forma parte del bloque de la constitucionalidad"33. Y con posterioridad, la Sala Constitucional al ratificar la existencia del bloque de la constitucionalidad integrado por la Constitución y los tratados sobre derechos humanos, incorporó a éste a las leyes constitucionales de descentralización previstas en el artículo 157 constitucional. Así, en el caso Analya Belisario y otros vs. Consejo Nacional Electoral, la Sala Constitucional dispuso lo siguiente: "Cabe agregar, que no sólo se circunscribe a servir de garantía de normatividad de la Constitución documental, sino que se extiende a todas las disposiciones del denominado bloque de la constitucionalidad, que comprende en Venezuela, a los tratados sobre derechos fundamentales, las eventuales leyes constitucional que pudieran dictarse conforme lo dispuesto en el artículo 157 de la Constitución y los principios que informan la parte dogmática de la misma" 34 .

Por su parte, la Corte Suprema de Justicia argentina, en el caso Jorge Rafael Videla ${ }^{35}$, declaró la inconstitucionalidad parcial del decreto de indulto presidencial a los miembros de la junta militar durante la dictadura, por resultar

\footnotetext{
32 Tribunal Supremo de Justicia de Venezuela ("TSJ"), caso Interpretación constitucional respecto al contenido y alcance del artículo 71 de la Constitución de la República Bolivariana de Venezuela. Sala Constitucional (“SC"). Sentencia de 22 de enero de 2003, No 23, disponible en: http://www.tsj.gov. ve/decisiones/scon/Enero/03-0017.html

${ }_{33}$ TSJ, caso Interpretación sobre el contenido y alcance del artículo 72 de la Constitución de la República Bolivariana de Venezuela. SC. Sentencia de 15 de junio de 2004, No 1173, disponible en: http://www. tsj.gov.ve/decisiones/scon/Junio/1173-150604-02-3215.html

${ }^{34}$ TSJ, caso Analya Belisario y otros. SC. Sentencia de 13 de julio de 2011, No 1089, disponible en: http://www.tsj.gov.ve/decisiones/scon/Julio/1089-13711-2011-10-1369.html

${ }_{35}$ Corte Suprema de Justicia de Argentina, caso Jorge Rafael Videla. Sentencia 21 de agosto de 2003.
} 
violatorio de los instrumentos internacionales sobre derechos humanos incluida la CADH que tienen jerarquía constitucional (art. 75, inciso 22), invocando para ello diversos casos de la Corte Interamericana de Derechos Humanos ("Corte IDH") y en especial el caso Barrios Altos vs. Perü ${ }^{36}$.

En esta línea de jurisprudencia constitucional, también la Sala Constitucional de la Corte Suprema de Justicia de Costa Rica, al resolver la consulta sobre el Proyecto de Ley para aprobar El Estatuto de Roma, reiteró su jurisprudencia sobre la jerarquía constitucional de los instrumentos sobre derechos humanos, al sostener que éstos "tienen no solamente un valor similar a la Constitución Política, sino que en la medida en que otorguen mayores derechos o garantías a las personas, priman por sobre la Constitución" ${ }^{37}$.

La Corte Constitucional colombiana en diversos casos, ha venido conformando la noción del bloque de la constitucionalidad, primero, incorporando a los tratados sobre derechos humanos, y segundo, a la jurisprudencia internacional. En este sentido, la Corte Constitucional en el caso demanda de Inconstitucionalidad contra las Expresiones "Grave” (Articulos de la Ley 599 de 2000 por la cual se expide el Código Penal), reiteró su doctrina sobre un bloque de constitucionalidad, integrado por: "(i) el preámbulo, (ii) el articulado de la Constitución, (iii) algunos tratados y convenios internacionales de derechos humanos ([Constitución Política] artículo 93), (iv) las leyes orgánicas y, (v) las leyes estatutarias"38. La Corte Constitucional colombiana también ha incorporado de una manera progresiva al bloque de la constitucionalidad las decisiones de los organismos internacionales creados por esos tratados de derechos humanos, en virtud de lo cual, evidentemente ha incluido la jurisprudencia de la Corte IDH ${ }^{39}$.

Por su parte, la Suprema Corte de Justicia de República Dominicana, también ha afirmado la existencia de un bloque de la constitucionalidad de doble fuente, integrado por la constitución y los tratados sobre derechos

\footnotetext{
${ }^{36}$ Corte IDH, caso Barrios Altos vs. Perú. Fondo. Sentencia de 14 de marzo de 2001.

37 Sala Constitucional de la Corte Suprema de Justicia de Costa Rica, Consulta sobre el Proyecto de Ley para aprobar El Estatuto de Roma. Resolución de 1 de noviembre de 2000 No 2000-09685 y ver sentencia No 2313-95.

${ }^{38}$ Corte Constitucional de Colombia. Sentencia de 22 de febrero de 2005, C- 148/05.

${ }^{39}$ Cfr. Corte Constitucional de Colombia, caso Jaime Rodríguez vs. Iván Mejía Álvarez, Sentencia de 7 de diciembre de 2001, T-1319/01.
} 
humanos, incluida la jurisprudencia de la Corte IDH, la cual es de "carácter vinculante" ${ }^{40}$. La Sala Constitucional salvadoreña, incluso sin fundamento constitucional expreso, ha sido progresiva al incorporar indirectamente ("por vía refleja") los instrumentos internacionales sobre derechos humanos al bloque de la constitucionalidad ${ }^{41}$.

En conclusión, en el sistema constitucional venezolano, por disposición expresa del artículo 23 del texto fundamental, los tratados relativos a los derechos humanos tienen la jerarquía constitucional, como es el caso de la $\mathrm{CADH}$, lo cual conlleva como consecuencia, la incorporación de todos estos tratados al bloque de la constitucionalidad o bloque de la constitución. El acto de denuncia de la $\mathrm{CADH}$, desconoció así la jerarquía constitucional de la Convención Americana, al pretender de manera arbitraria su desincorporación del bloque de la constitucionalidad.

\section{La violación de la supremacía constitucional}

La supremacía de la constitución sobre el resto del ordenamiento jurídico interno está representada en la imposibilidad de que ella sea modificada o derogada por mecanismos ordinarios, incluso los establecidos para la legislación. La supremacía y la consecuente garantía de la rigidez de la constitución significan la inhabilidad del Poder Ejecutivo (y en su caso incluso del Poder Legislativo ordinario) para modificar la Constitución. De esta forma, la supremacía de la Constitución es la primera condición para existencia misma de un orden jurídico constitucional ${ }^{42}$. La supremacía constitucional es así una característica fundamental del Estado Constitucional mismo, por lo que una de las funciones de la Constitución es precisamente excluir materias de la libre disposición del poder constituido ordinario, y especialmente de los poderes ejecutivo y judicial ${ }^{43}$.

\footnotetext{
${ }^{40}$ Suprema Corte de Justicia de República Dominicana. Resolución de 13 de noviembre de 2003, No 1920-2003.

${ }^{41}$ Sala Constitucional de El Salvador, caso Inconstitucionalidad de la Ley Anti Maras. Sentencia de 1 de abril de 2004, No 52-2003/56-2003/57-2003.

${ }^{42}$ GuASTI, Ricardo: "La constitucionalización del ordenamiento jurídico: el caso italiano" en CARBONeLL SÁncheZ, Miguel (coord.): Neoconstitucionalismo(s), México, 2003, pp. 49-74.

${ }^{43}$ Häberle, Peter: El Estado Constitucional, Astrea, Buenos Aires, 2007, pp. 220-230.
} 
En este sentido, la consecuencia jurídica de que los tratados sobre derechos humanos tengan jerarquía constitucional y, por tanto, integren el bloque de la constitucionalidad es que vinculan con esa jerarquía en el derecho interno al resto del ordenamiento jurídico y a todos los Poderes Públicos, los cuales deben sujetarse a ellos en igual medida que a la propia Constitución. Por lo cual, al igual que la Constitución, la CADH como tratado relativo a los derechos humanos es "la norma suprema y el fundamento del ordenamiento jurídico" por lo que "todas las personas y los órganos que ejercen el Poder Público están sujetos” a ellos ${ }^{44}$. De allí que todo acto del poder público que viole o menoscabe los derechos garantizados en la $\mathrm{CADH}$ es nulo; y los funcionarios públicos que lo ordenen o ejecuten incurren en responsabilidad penal, civil y administrativa, según los casos, sin que les sirvan de excusa órdenes superiores $^{45}$. Y, todos los jueces, al estar obligados a asegurar la integridad de la Constitución, deben igualmente garantizar la integridad de los tratados relativos a derechos humanos ${ }^{46}$.

En el caso de los tratados relativos a los derechos humanos como es el caso de la $\mathrm{CADH}$, su incorporación al bloque de la constitucionalidad en virtud del artículo 23, trae como consecuencia necesariamente, su supremacía constitucional. De allí que la protección formal de la supremacía de la Constitución está contenida en la rigidez para su reforma -en los casos permitidosmediante los procedimientos agravados y especiales establecidos en el propio Texto Fundamental, incluida la consulta popular aprobatoria ${ }^{47}$.

No obstante, en virtud del principio de progresividad en materia de derechos humanos, un tratado sobre derechos humanos con jerarquía constitucional no podría denunciarse mediante la enmienda, la reforma o incluso una asamblea nacional constituyente, ya que significaría una regresión inaceptable de una protección más favorable.

Por ello, una vez incorporado un tratado relativo a derechos humanos al bloque de la constitucionalidad como es el caso de la CADH, el mismo sólo podrá ser denunciado -en los casos en que proceda conforme al derecho internacional y al derecho constitucional- siguiendo para ello los procedi-

\footnotetext{
${ }^{44}$ Artículo 7, CRBV.

${ }^{45}$ Artículo 25, CRBV.

${ }^{46}$ Artículo 334, encabezamiento, CRBV.

${ }^{47}$ Artículos 340 a 346, CRBV.
} 
mientos especiales de modificación o de creación de una nueva constitución. Decimos en los casos en que proceda conforme al derecho internacional, porque dada la naturaleza propia de los tratados de derechos humanos, si éstos no establecen una cláusula expresa para su denuncia, ésta no es posible. Tal es el caso por ejemplo, del Pacto Internacional de Derechos Civiles y Políticos, conforme al criterio establecido por el Comité de Derechos Humanos de las Naciones Unidas ${ }^{48}$.

El principio de la supremacía constitucional de los tratados de derechos humanos se justifica además en que "fue la intención del constituyente cerrar un sistema de protección de las normas sobre derechos humanos que le impida al Poder Ejecutivo denunciar un tratado con el fin de sortear la responsabilidad internacional que pudiera atribuírsele por incumplimiento de algunas de sus normas" ${ }^{49}$.

Así por ejemplo, en el caso de Argentina, conforme a la norma constitucional del artículo 75 inciso 22, los tratados sobre derechos humanos gozan de la misma jerarquía que la Constitución y por tanto de su supremacía. Por ello, esos tratados sólo pueden ser denunciados previo cumplimiento de un procedimiento agravado, previsto en la Constitución: la previa aprobación de las dos terceras partes de la totalidad de los miembros de cada Cámara. La rigidez constitucional de los tratados de derechos humanos ha sido fundada además en el principio del paralelismo de competencias entre los poderes del Estado $^{50}$. Según este principio, las mismas voluntades que se requieren para celebrar, aprobar y ratificar un tratado deben estar presentes para su denuncia. Es decir, si en la negociación, firma y ratificación del tratado interviene el Poder Ejecutivo, y en su aprobación interviene el Poder Legislativo; entonces en la autorización de la denuncia debe intervenir el Poder Legislativo y en la denuncia internacional, el Poder Ejecutivo.

\footnotetext{
${ }^{48}$ Ver el criterio del Comité de Derechos Humanos del Pacto Internacional de Derechos Civiles y Políticos de la ONU, frente a la pretendida denuncia del Pacto Internacional de Derechos Civiles y Políticos por Corea del Norte, en Recopilación de las Observaciones Generales y Recomendaciones Generales Adoptadas por los Órganos de Derechos Humanos creados en virtud de Tratados, Instrumentos Internacionales de Derechos Humanos, Naciones Unidas, HRI/GEN/1/Rev. 3.

49 Cafiero, Juan Pablo; Ruth Faur, Marta; Llamosas, Esteban Miguel; Méndez, Juan; Ponce León, Rodolfo, y Vallejos, Cristina María: Jerarquía Constitucional de los tratados internacionales, Astrea, Buenos Aires, 1996, p. 52.

${ }^{50}$ CAFiero, Juan Pablo; y otros, op. cit., pp. 52 y 53.
} 
En Venezuela a pesar de que hemos sostenido que los tratados sobre derechos humanos no pueden denunciarse ni siquiera enmendando ni reformando la Constitución ni dictando una nueva, en todo caso, como base mínima debe aplicarse el principio de la supremacía constitucional y la consecuente rigidez constitucional previsto en la Constitución conforme al cual, "Esta Constitución no perderá su vigencia si dejare de observarse por acto de fuerza o porque fuere derogada por cualquier otro medio distinto al previsto en ella" ${ }^{51}$. Por lo cual, si un tratado sobre derechos humanos con jerarquía y supremacía constitucional, como es el caso de la $\mathrm{CADH}$, que integra por tanto el bloque de la constitucionalidad, pretende ser desprendido de la Constitución por el Poder Ejecutivo -como ha sido el caso de su denuncia-, dicho acto es groseramente violatorio de la Constitución, al pretender modificarla por un medio distinto al previsto en ella. La sanción a esa violación constitucional no es otra, que su nulidad.

\section{A. La violación expresa del artículo 339 de la Constitución}

En el presente caso, la denuncia de la $\mathrm{CADH}$ no sólo viola la jerarquía y supremacía constitucional en general de todos los tratados sobre derechos humanos consagrada en el artículo 23 constitucional, sino que además viola directamente al artículo 339 de la Constitución el cual incorpora expresamente a ese instrumento internacional en su normativa. En efecto, el artículo 339 de la Constitución establece:

Artículo 339. El decreto que declare el estado de excepción, en el cual se regulará el ejercicio del derecho cuya garantía se restringe, será presentado dentro de los ocho días siguientes de haberse dictado, a la Asamblea Nacional, o a la Comisión Delegada, para su consideración y aprobación, y a la Sala Constitucional del Tribunal Supremo de Justicia, para que se pronuncie sobre su constitucionalidad. El decreto cumplirá con las exigencias, principios y garantias establecidos en el Pacto Internacional de Derechos Civiles y Políticos y en la Convención Americana sobre Derechos Humanos. El Presidente o Presidenta de la República podrá solicitar su prórroga por un plazo igual, y será revocado por el Ejecutivo Nacional o por la Asamblea Nacional o por su Comisión Delegada, antes del término señalado, al cesar las causas que lo motivaron. (Resaltados añadidos).

${ }^{51}$ Artículo 333, CRBV. 
La decisión del Constituyente, de incorporar expresamente a la CADH al articulado o normativa de la Constitución en su artículo 339, es una consecuencia lógica de la jerarquía y supremacía otorgada a dicho instrumento de jerarquía constitucional por el artículo 23. Ello es, en las condiciones de un tratado de derechos humanos ratificado por Venezuela y por tanto vigente, el ordenamiento constitucional conformado por el bloque de la constitucionalidad, pasó a regirse no sólo por su normativa sino además como obligación constitucional en el derecho interno por dicho instrumento. En otras palabras, el Constituyente reforzó las obligaciones internacionales derivadas de la $\mathrm{CADH}$ convirtiéndolas además en obligaciones internas constitucionales. Es evidente por tanto que, habiendo sido incorporada al bloque de la constitucionalidad como un tratado relativo a derechos humanos, la CADH pasó además a integrar expresamente a la Constitución misma.

Como consecuencia de ello, no puede el Poder Ejecutivo modificar la Constitución al pretender modificar el artículo 339, mediante la denuncia inconstitucional de la $\mathrm{CADH}$.

Al igual que la violación del artículo 23 constitucional argumentada supra, en este caso se trata de una clara usurpación de autoridad, ya que en ningún caso tiene competencia el Presidente de la República ni sus Ministros para modificar la Constitución. Como argumentamos, la Constitución establece los mecanismos para su modificación (enmienda o reforma ${ }^{52}$ ) o para dictarse una nueva constitución (asamblea nacional constituyente ${ }^{53}$ ). Por lo que conforme la propia Constitución, ésta no perderá su vigencia si "fuere derogada por cualquier otro medio distinto al previsto en ella" 54 .

En consecuencia, de conformidad con lo dispuesto en la propia Constitución, la denuncia de la CADH es "ineficaz" por tratarse de un acto producto de una autoridad usurpada por el Poder Ejecutivo Nacional, y la sanción a esta usurpación, por expresa disposición constitucional, es que dicho acto es "nulo" 55 .

\footnotetext{
${ }^{52}$ Artículos 340 a 347, CRBV.

53 Artículos 347 a 349, CRBV.

${ }^{54}$ Artículo 333, CRBV.

55 Artículo 138, CRBV.
} 


\section{LA VIOLACIÓN DEL DERECHO DE PETICIÓN INTERNACIONAL CONSAGRADO EN EL ARTí́CUlo 31 DE La CONSTITUCión}

El artículo 31 constitucional reconoce el derecho de toda persona de petición, tutela, protección o amparo internacional de sus derechos humanos, en los términos siguientes:

Artículo 31. Toda persona tiene derecho, en los términos establecidos por los tratados, pactos y convenciones sobre derechos humanos ratificados por la República, a dirigir peticiones o quejas ante los órganos internacionales creados para tales fines, con el objeto de solicitar el amparo a sus derechos humanos.

El Estado adoptará, conforme a procedimientos establecidos en esta Constitución y en la ley, las medidas que sean necesarias para dar cumplimiento a las decisiones emanadas de los órganos internacionales previstos en este artículo. (Textos cursivos añadidos).

Esta norma consagra en el ordenamiento venezolano, la constitucionalización del derecho de petición internacional de toda persona, establecido y regulado en los tratados, pactos y convenciones internacionales, para solicitar el amparo a los derechos humanos. La denuncia de la $\mathrm{CADH}$ constituye una violación por desconocimiento de este derecho denominado reconocido en el artículo 31 constitucional.

Este derecho de petición internacional consiste en el derecho de todas las personas a acceder a los órganos internacionales para que conozcan de las denuncias de violaciones a derechos humanos sobre las cuales tengan competencia y en su caso, para obtener de dichos órganos la protección efectiva. El derecho por tanto no se limita formalmente al derecho de acceder a dichos órganos, sino se extiende al derecho de una tutela efectiva por parte de los órganos internacionales a los cuales se acceda. En este sentido, la norma prevista en el artículo 31 constitucional no se limita al mero conocimiento de los órganos internacionales, sino a la obligatoriedad del Estado a que dichas situaciones violatorias a derechos humanos sean reparadas de manera efectiva. $\mathrm{La} \mathrm{CADH}$ establece dos órganos de protección internacional de los derechos en ella reconocidos: la Comisión Interamericana de Derechos Humanos ("CIDH") y la Corte IDH.

En este sentido, desde la aprobación legislativa de la CADH (14-6-77) y su ratificación mediante el depósito del instrumento respectivo en la Secretaría General de la OEA (8-9-77) y posteriormente, con la aceptación de la juris- 
dicción contenciosa obligatoria de la Corte IDH (6-4-81), todas las personas (individuos) bajo la jurisdicción del Estado Venezolano, han sido titulares del derecho convencional de acceder a la tutela o protección internacional de los derechos humanos reconocidos en la $\mathrm{CADH}$, ante los dos órganos respectivos (CIDH y Corte IDH), en los términos previstos en dicho tratado. Este derecho convencional de toda persona de petición internacional ante el sistema interamericano de protección de los derechos humanos, quedó constitucionalizado por disposición del artículo 31 del texto fundamental de 1999. Por lo cual, no puede pretenderse su eliminación o desgarre mediante la denuncia por el Ejecutivo Nacional de la CADH.

En efecto, los tratados sobre derechos humanos como la CADH no sólo reconocen derechos fundamentales sustantivos cuyas obligaciones internacionales de respeto y garantía le corresponde a los Estados parte; si no que además, algunos de éstos, como la $\mathrm{CADH}$, establecen órganos y mecanismos internacionales de protección de esos derechos, cuando las violaciones a los mismos no son reparadas de manera efectiva y oportuna mediante los recursos judiciales internos.

Por lo cual, cuando las violaciones a los derechos humanos no son reparadas por los mecanismos de derecho interno, la jurisdicción estatal o interna debe considerarse agotada conforme a las reglas y excepciones del derecho internacional $y$, en consecuencia, se habilita a las personas para acudir a la protección internacional de los derechos humanos. Este último mecanismo que ha sido denominado el "amparo internacional", Cappelletti lo concibió como un amparo individual a nivel supranacional, el cual se ejerce con base en un "bill of rights transnacional" ante un organismo también transnacional (la Comisión Europea y la Corte Europea de Derechos Humanos) ${ }^{56}$. Por su parte, Gimeno Sendra emplea el término de "amparo internacional" para referirse a las reclamaciones individuales de las personas (víctimas) ante la Corte Europea de Derechos Humanos frente a las lesiones a sus derechos humanos o libertades fundamentales provenientes de los poderes públicos de los Estados integrados al Consejo de Europa y signatarios del Convenio Europeo sobre Derechos Humanos ${ }^{57}$. En efecto, con ocasión de la entrada

${ }^{56}$ Cappelletti, Mauro: Dimensiones de la Justicia en el Mundo Contemporáneo, Editorial Porrúa, C.A., México, 1993, pp. 45 y siguientes.

57 Gimeno Sendra, Vicente, y Garberi LL., José: Los procesos de amparo (ordinario constitucional e internacional), Madrid, 1994, pp. 237 y ss. 
en vigencia del Protocolo Adicional No 12, la Comisión y la Corte Europeas se habrán fusionado a finales de 1998 en un solo órgano denominado Tribunal (o Corte) Europeo de Derechos Humanos, al cual podrán acudir directamente las víctimas de violación de sus derechos humanos bajo el Convenio Europeo ${ }^{58}$.

Ahora bien, en el caso concreto de los Estados como Venezuela que ratificaron la $\mathrm{CADH}$, este derecho que hemos denominado el amparo interamericano ${ }^{59}$, está consagrado expresamente en dicho instrumento como una acción popular, en los siguientes términos:

Artículo 44. Cualquier persona o grupo de personas, o entidad no gubernamental legalmente reconocida en uno o más Estados miembros de la Organización, puede presentar a la Comisión peticiones que contengan denuncias o quejas de violación de esta Convención por un Estado parte.

Evidentemente, para que una petición sea admisible es necesario que se hayan agotado los recursos de la jurisdicción interna, o se encuentre ante una de las excepciones previstas en la $\mathrm{CADH}^{60}$.

Conforme a la CADH, el procedimiento de tramitación de un caso ante la $\mathrm{CIDH}$ incluye las fases procesales de admisibilidad, audiencias, ofrecimiento de la solución amistosa, pruebas, informe preliminar de fondo del artículo 50, e informes definitivos del artículo 51. Los informes de la CIDH normalmente terminan con: A) Las conclusiones, en las cuales se determina si el Estado ha violado los derechos humanos reconocidos en la CADH y, en caso de que ello sea así, declarar su responsabilidad internacional; y B) Las recomendaciones, mediante las cuales se le señala al Estado las medidas que debe adoptar para restablecer la situación jurídica infringida, y efectuar las reparaciones e indemnizaciones pertinentes. Durante el plazo de los tres (3) meses siguientes a partir de la remisión al estado del referido informe, la $\mathrm{CIDH}$ debe determinar si el Estado no ha solucionado el asunto: y en el supuesto

\footnotetext{
${ }^{58}$ Protocol No 11 to the Convention for the Protection of Human Rights and Fundamental Freedoms Restructuring the Control Machinery Established Thereby, November 1. 1997, Council of Europe, versión original en inglés.

59 Sobre el amparo interamericano, ver nuestro libro: Ayala CoRAO, Carlos: Del amparo constitucional al amparo interamericano como institutos para la protección de los derechos humanos. Instituto Interamericano de Derechos Humanos y Editorial Jurídica Venezolana. Caracas/San José, 1998.

${ }^{60}$ Artículo 46, CADH.
} 
de que dicho Estado haya reconocido la jurisdicción obligatoria contenciosa de la Corte IDH (ej. Venezuela), la CIDH (o el Estado parte) puede someter el caso ante la Corte IDH ${ }^{61}$.

Si no somete el caso ante la Corte IDH, la CIDH debe emitir un informe con las conclusiones y recomendaciones, el cual dirigirá al Estado, (y a los peticionarios) y fijará un plazo para su cumplimiento. Vencido este plazo, la CIDH debe decidir, por la mayoría absoluta de sus miembros, si el Estado ha adoptado o no las medidas adecuadas y si publica o no su informe ${ }^{62}$.

De esa forma, el proceso ante la Corte IDH se inicia con el envío del caso por la CIDH, y se sustancia con la participación directa de la víctima (o sus familiares y representantes) así como del Estado demandado. Luego de su tramitación, el caso culmina con la sentencia o fallo (excepciones preliminares, fondo y reparaciones) la cual se pronuncia igualmente sobre la violación de los derechos humanos reconocidos en la $\mathrm{CADH}$ por parte del Estado con la declaración su responsabilidad internacional, establece las reparaciones e indemnizaciones compensatorias correspondientes. En este sentido, la Corte IDH ejerce una jurisdicción contenciosa plena, ya que cuando decide que ha habido violación de un derecho protegido por la $\mathrm{CADH}$, tiene poderes convencionales para disponer que se garantice al lesionado en el goce de su derecho o libertad o derechos conculcados; y asimismo, de resultar procedente, puede disponer que se reparen las consecuencias de la medida o situación que ha configurado la vulneración de esos derechos, y el pago de una justa indemnización a la parte lesionada ${ }^{63}$. La CADH refuerza la jurisdicción internacional plena reparatoria de la Corte IDH, al establecer el compromiso de los Estados parte de cumplir con sus decisiones en todo caso en que sean parte. Y con relación a la indemnización compensatoria que disponga el fallo, la CADH dispone incluso la ejecutabilidad u operatividad inmediata por el procedimiento interno para la ejecución de sentencias contra el Estado.

Todo ello permite configurar a la jurisdicción de la Corte IDH como una verdadera jurisdicción internacional de protección de las personas frente a las violaciones a los derechos humanos reconocidos en la $\mathrm{CADH}$, -atribuibles a

${ }^{61}$ Artículos 51 y 61, CADH.

${ }^{62}$ Artículo 51, CIDH.

${ }^{63}$ Artículo 63, CADH. 
los agentes de un Estado parte y que no hayan sido reparadas eficaz y oportunamente por la jurisdicción interna ${ }^{64}$.

En consecuencia, esta situación jurídica permite evidenciar la protección internacional de los derechos humanos como un derecho de todas las personas que hayan sido víctimas de una violación a los derechos reconocidos en la CADH por parte de un Estado parte de la misma.

Estos derechos y garantías sustantivos y particularmente el derecho procesal de toda persona a la solicitar la protección internacional de los derechos reconocidos en la CADH son desconocidos -conforme a las reglas de la competencia temporal dispuestas en el artículo 78 de la CADH- por el Gobierno de la República Bolivariana de Venezuela, con la denuncia de dicho instrumento internacional, ocasionando con ello la violación directa de este derecho reconocido en el artículo 31 de la Constitución.

Si bien el Estado venezolano sigue vinculado por siempre respecto a las obligaciones internacionales sustantivas y procesales de protección internacional ocurridas antes de la entrada en vigencia de la denuncia de la $\mathrm{CADH}$, una vez que entre en vigor esta denuncia -supuestamente el 10-9-13-, esta competencia excluirá su jurisdicción respecto de los hechos ocurridos posteriormente. Por lo cual, es evidente los efectos regresivos y excluyentes de la protección internacional de los derechos humanos que operarán una vez que entre en vigor la denuncia de dicho instrumento. En efecto, una vez que entre en vigor la denuncia de la $\mathrm{CADH}$, las personas bajo la jurisdicción del Estado Venezolano quedarán despojadas y por tanto, excluidas de este derecho de petición internacional bajo dicho instrumento, al removerle la competencia a la $\mathrm{CIDH}$ para conocer las denuncias de violaciones a la CADH ocurridas después de dicho término. E igualmente, a partir de la entrada en vigor de la denuncia, quedarán excluidas de manera definitiva la protección judicial internacional de las personas por parte de la Corte IDH para que tutele las violaciones a los derechos humanos -reconocidos en la $\mathrm{CADH}$ - ocurridas a partir de esa fecha.

Si bien la CIDH por ser un órgano principal de la Carta de la OEA, podrá seguir ejerciendo su jurisdicción sobre el Estado Venezolano para proteger a

\footnotetext{
${ }^{64} \mathrm{La}$ Corte IDH tiene atribuida además, una jurisdicción consultiva para interpretar la CADH u otros tratados concernientes a la protección de los derechos humanos en los Estados Americanos, a solicitud de éstos, de la CIDH y los demás órganos enumerados en el Capítulo X de la Carta de la OEA (artículo 64, CADH).
} 
las personas, ésta estará limitada desde de la entrada en vigor de la denuncia y respecto a los hechos ocurridos a partir de esa fecha, para plantear los casos únicamente con base en la Declaración Americana de los Derechos y Deberes del Hombre de $1948^{65}$-que no es un tratado-, el Estatuto ${ }^{66}$ y el Reglamento de la $\mathrm{CIDH}^{67}$.

Por lo cual, en las condiciones fácticas y jurídicas expuestas, una vez que entre en vigor la denuncia de la CADH y respecto a nuevos hechos no vinculados con hechos anteriores, las personas bajo la jurisdicción del Estado venezolano se verán además excluidas del derecho de solicitar a través de la $\mathrm{CIDH}$ la protección cautelar (medidas provisionales) por parte de la Corte IDH, y en general una decisión (sentencia) de fondo por parte de ese máximo tribunal hemisférico -respecto de las nuevas violaciones o hechos que ocurran una vez que entre en vigencia la denuncia de la $\mathrm{CADH}$.

En este sentido, con ocasión del preaviso de la denuncia dado por el Gobierno de Venezuela el 10-09-12, la CIDH manifestó con mucha claridad, su preocupación sobre los efectos regresivos de esta denuncia, afirmando que "a partir de la entrada en vigencia de la denuncia, las violaciones a los derechos humanos que pudieran ocurrir en Venezuela no podrán ser conocidas por la Corte IDH. Esto significa que, si el Estado lleva a término el procedimiento iniciado, los y las habitantes de Venezuela perderán una instancia de protección de sus derechos humanos, quedarán más vulnerables a los abusos y tendrán menos recursos disponibles para defenderse". Añadió la Comisión que,

Al crear la OEA en 1948, los Estados expresaron como un objetivo de la Organización el "consolidar en este Continente, dentro del marco de las instituciones democráticas, un régimen de libertad individual y de justicia social, fundado en el respeto de los derechos esenciales del hombre". En ese espíritu, los Estados crearon

\footnotetext{
${ }^{65}$ Declaración Americana de los Derechos y Deberes del Hombre. Aprobada en la Novena Conferencia Internacional Americana. Bogotá, Colombia, 1948. Disponible en: http://www.cidh.org/basicos/Basi$\cos 1 . h$ tm.

${ }^{66}$ Estatuto de la Comisión Interamericana de Derechos Humanos. Aprobado mediante la Resolución No 447 adoptada por la Asamblea General de la OEA en su noveno período ordinario de sesiones, celebrado en La Paz, Bolivia, octubre de 1979. Disponible en: http://www.cidh.org/basicos/basicos9. htm.

${ }^{67}$ Reglamento de la Comisión Interamericana de Derechos Humanos. Aprobado por la Comisión en su $13^{\circ} 7$ período ordinario de sesiones, celebrado del 28 de octubre al 13 de noviembre de 2009. Disponible en: http://www.cidh.org/basicos/basicos10.htm.
} 
el sistema interamericano de derechos humanos con el mandato de supervisar el respeto y la garantía de los derechos humanos de todas las personas en la región. Los Estados miembros y los órganos políticos de la OEA constituyen la garantía colectiva de ese sistema. Teniendo esto en consideración, la CIDH hace un llamado al Estado de Venezuela para que reconsidere su decisión de denunciar la Convención Americana.

En caso que el procedimiento llegue a término y la denuncia de la Convención cobre vigencia en el plazo de un año, la Comisión continuará con el procesamiento de peticiones y de solicitudes de medidas cautelares relativas a Venezuela, así como con la supervisión de la situación de derechos humanos en ese país, en base al artículo 106 de la Carta de la OEA y la Declaración Americana. ${ }^{68}$

Es precisamente por este efecto de "desprotección internacional" de las personas en Venezuela, que el Secretario General de la OEA al acusar el recibo de la denuncia de la CADH por parte del Gobierno de Venezuela, "lamentó esta decisión ya que dicha Convención constituye uno de los pilares de la normativa legal que ampara la defensa de los derechos humanos en el continente" ${ }^{69}$.

Resulta evidente por tanto, que la denuncia de la de la CADH por el Gobierno de Venezuela, constituye una franca violación al artículo 31 constitucional, al disminuir y en su caso excluir arbitrariamente a todas las personas del derecho a solicitar y obtener ante la CIDH y en su caso ante la Corte IIDH la protección internacional efectiva frente a la violación de los derechos reconocidos en dicha Convención.

\section{LA VIOLACIÓN DEL PRINCIPIO DE LA PROGRESIVIDAD DE LOS DERECHOS HUMANOS CONSAGRADO EN EL ARTí́CUlo 19 DE LA CONSTITUCIÓN}

El artículo 19 de la Constitución reconoce constitucionalmente el principio de progresividad de los derechos humanos, al establecer que:

\footnotetext{
${ }^{68}$ OEA, CIDH lamenta decisión de Venezuela de denunciar Convención Americana sobre Derechos Humanos, 12 de septiembre de 2012, disponible en: http://www.oas.org/es/cidh/prensa/comunicados/2012/117. asp

69 OEA, Secretario General de la OEA comunica denuncia de la Convención Americana sobre Derechos Humanos de parte de Venezuela, Comunicado C-307/12, 10 de septiembre de 2012, disponible en: http:// www.oas.org/es/centro_noticias/comunicado_prensa.asp?sCodigo=C-307/12
} 
El Estado garantizará a toda persona, conforme al principio de progresividad y sin discriminación alguna, el goce y ejercicio irrenunciable, indivisible e interdependiente de los derechos humanos. Su respeto y garantía son obligatorios para los órganos del Poder Público de conformidad con esta Constitución, con los tratados sobre derechos humanos suscritos y ratificados por la República y con las leyes que los desarrollen. (Cursivas añadidas).

Esta norma constitucional fundamental en materia de derechos humanos, producto de su evolución originalmente en el ámbito internacional, es una consecuencia necesaria de la norma consagrada en el artículo $2^{\circ}$ constitucional, la cual establece la preeminencia de los derechos humanos como Principio Fundamental de nuestro ordenamiento jurídico. Este principio conlleva la necesidad de interpretar y aplicar todo el ordenamiento jurídico del Estado Venezolano de conformidad con la preeminencia de los derechos humanos, obteniendo como resultado, un plexo de valores y normas que garanticen su respeto, garantía y protección efectiva.

De esta manera, el principio de progresividad conlleva como contenido esencial, el deber del Estado de adoptar siempre la conducta que más favorezca el respeto, la garantía y la protección de los derechos humanos. Al mismo tiempo, la progresividad conlleva como principio la irreversibilidad de los derechos que han sido ya reconocidos como tales; es decir, que una vez que han sido reconocidos como derechos inherentes a la persona humana, no pueden ser desconocidos ni disminuidos como tales ${ }^{70}$. Por ello, la progresividad trae consigo las siguientes obligaciones del Estado de: (i) reconocer, respetar, garantizar y proteger los derechos humanos; (ii) mantener el avance sostenido de los derechos, tanto en lo referente a la ampliación de su contenido, al reconocimiento de nuevos derechos y a la ampliación de los ya existentes; (iii) interpretar de la manera más favorable a las personas los derechos reconocidos y por tanto, no restringir de manera inaceptable o arbitraria los derechos humanos ya reconocidos; y finalmente, (iv) no revertir un derecho ya reconocido.

En este sentido, el propio Preámbulo de la Constitución expresa que ella se adopta en "ejercicio de su poder originario representado por la Asamblea Nacional Constituyente mediante el voto libre y en referendo democrático"

\footnotetext{
70 Nikren, Pedro: La Protección Internacional de los Derechos Humanos: Su Desarrollo Progresivo, Editorial Instituto Interamericano de Derechos Humanos, Madrid, España. 1987. Extraído de: http://www. bibliojuridica.org/libros/libro.htm?l=2037
} 
que estableció como propósito fundamental de la nueva Carta Fundamental "la garantía universal e indivisible de los derechos humanos". En este sentido es importante puntualizar, que el principio de progresividad de los derechos humanos -como expusimos supra- encuentra fundamento no sólo en las normas constitucionales citadas, sino además en la Base Comicial Octava de la aprobación de la convocatoria a la Asamblea Nacional Constituyente, la cual expresamente dispuso que:

Una vez instalada la Asamblea Nacional Constituyente, como poder originario que recoge la soberanía popular, deberá dictar sus propios estatutos de funcionamiento, teniendo como límites los valores y principios de nuestra historia republicana, así como el cumplimiento de los tratados internacionales, acuerdos y compromisos válidamente suscritos por la República, el carácter progresivo de los derechos fundamentales del hombre y las garantías democráticas dentro del más absoluto respeto de los compromisos asumidos. (Resaltados y cursivas añadidos).

Ello significa, como se dijo, que los derechos consagrados por la Constitución no pueden ser posteriormente desconocidos ni disminuidos, ya que su naturaleza de ser "inherentes a la persona" una vez reconocidos no puede ser revertidos ${ }^{71}$.

De esta forma, la protección de los derechos humanos se plasma en un régimen siempre susceptible de ampliación, mas no de regresión ni de exclusión. Es por ello, que la mayoría de los tratados sobre derechos humanos incluyen una cláusula según la cual, ninguna disposición convencional puede menoscabar la protección más amplia que puedan brindar otras normas de derecho interno o de derecho internacional. En este sentido la propia $\mathrm{CADH}$ igualmente establece las siguientes reglas de interpretación, que confirman la progresividad de los derechos humanos:

Artículo 29. Normas de Interpretación

Ninguna disposición de la presente Convención puede ser interpretada en el sentido de:

a) permitir a alguno de los Estados partes, grupo o persona, suprimir el goce y ejercicio de los derechos y libertades reconocidos en la Convención o limitarlos en mayor medida que la prevista en ella;

b) limitar el goce y ejercicio de cualquier derecho o libertad que pueda estar reconocido de acuerdo con las leyes de cualquiera de los Estados partes o de acuerdo con otra convención en que sea parte uno de dichos Estados;

${ }^{71}$ Artículo 22, CRBV. 
c. excluir otros derechos y garantías que son inherentes al ser humano o que se derivan de la forma democrática representativa de gobierno, y

d. excluir o limitar el efecto que puedan producir la Declaración Americana de Derechos y Deberes del Hombre y otros actos internacionales de la misma naturaleza.

En esta dirección, la Corte IDH ha señalado que, "si a una misma situación son aplicables la Convención Americana y otro tratado internacional, debe prevalecer la norma más favorable a la persona humana" (Cursivas añadidas) ${ }^{72}$. Incluso la Sala Constitucional de Venezuela, al pronunciarse sobre las pautas interpretativas del principio de progresividad de los derechos humanos, ha afirmado que dicho principio se materializa a través de una estructura tridimensional, compuesta por (1) la obligación del Estado de permitir y promover el incremento del número de derechos humanos, (2) permitir y promover el crecimiento de la esfera de protección de dichos derechos, y finalmente, (3) fortalecer los mecanismos de tutela de dichos derechos. En este sentido, la Sala Constitucional estableció la siguiente interpretación constitucional vinculante sobre la progresividad de los derechos:

El texto constitucional reconoce de manera expresa el principio de progresividad en la protección de los derechos humanos, según el cual, el Estado se encuentra en el deber de garantizar a toda persona natural o jurídica, sin discriminación de ninguna especie, el goce y ejercicio irrenunciable, indivisible e interdependiente de tales derechos. Tal progresividad se materializa en el desenvolvimiento sostenido, con fuerza extensiva, del espectro de los derechos fundamentales en tres dimensiones básicas, a saber, en el incremento de su número, en el desarrollo de su contenido, y en el fortalecimiento de los mecanismos institucionales para su protección. En este ámbito cobra relevancia la necesidad de que la creación, interpretación y aplicación de las diversas normas que componen el ordenamiento jurídico, se realice respetando el contenido de los derechos fundamentales. (Textos cursivos añadidos) ${ }^{73}$.

Por lo cual, conforme a la interpretación vinculante realizada incluso por la Sala Constitucional de Venezuela, el principio de progresividad reconocido en la propia Constitución prohíbe la regresividad de los derechos humanos, por

72 Corte IDH, La Colegiación Obligatoria de Periodistas, Opinión Consultiva OC-5/85 del 13 de noviembre de 1985, Serie A No 5, párr. 52.

${ }^{73}$ TSJ, caso Desaplicación por control difuso del segundo aparte del artículo 376 del COPP. SC. Sentencia de 6 de febrero de 2007, N 161; caso Acción de Nulidad por Inconstitucionalidad contra el artículo 493 COPP. SC. Sentencia de 7 de agosto de 2007 No 1709. 
lo que está vedada la reducción de los derechos humanos, la reducción de la esfera de protección de derechos humanos de las personas, y con más razón, la eliminación de los mecanismos existentes para su protección.

No obstante, el acto de Gobierno de Venezuela mediante el cual el su Ministro de Relaciones Exteriores formalizó ante la Secretaría General de la OEA la denuncia de la $\mathrm{CADH}$, constituye en una evidente regresión de los derechos humanos, en evidente violación al principio de progresividad consagrado en el artículo 19 constitucional, en virtud de que mediante dicho acto: (i) no sólo se eliminan hacia el futuro y respecto de los hechos ocurridos con posterioridad a la entrada en vigor de la denuncia, las obligaciones internacionales sustantivas de garantía y respeto de los derechos reconocidos en dicho instrumento internacional; sino que además, (ii) conforme se detallará infra, hacia el futuro $y$ respecto de los hechos ocurridos con posterioridad, se elimina el derecho de todas las personas, reconocido en dicho instrumento internacional, de la protección internacional de las violaciones a sus derechos humanos igualmente reconocidos en la CADH, por ante la CIDH y la Corte IIDH, -derecho igualmente reconocido expresamente en el artículo 31 constitucional, conforme al cual, " $[\mathrm{t}]$ oda persona tiene derecho (...) a dirigir peticiones o quejas ante los órganos internacionales creados para tales fines, con el objeto de solicitar el amparo a sus derechos humanos"-.

Precisamente la CADH es un instrumento internacional que (desde su aprobación publicada en G.O. No 31.256 del 14 de junio de 1977, cuya ratificación fue depositada el 9 de agosto de 1977 ante la Secretaría General de la OEA, y cuya aceptación de la jurisdicción de la Corte IDH fue igualmente depositada el 24 de junio de 1981), en primer lugar, reconoce el deber del Estado y como contrapartida el derecho de todas las personas bajo la jurisdicción del Estado Venezolano de hacer valer sus derechos humanos reconocidos en esta Convención; y en segundo lugar, reconoce el derecho de toda persona a la protección internacional de los derechos convencionales, cuando el Estado no ha podido protegerlos mediante una justicia efectiva, oportuna e idónea. En este sentido, en virtud del sistema de protección internacional de los derechos humanos reconocido en dicho tratado, primero la $\mathrm{CIDH}$ y luego concretamente la Corte IDH, cuya competencia compulsoria fue reconocida "de pleno derecho y sin convención especial" por Venezuela el 24 de junio de 1981 de conformidad con el artículo 62 de la CADH, ha podido brindar justicia a favor de diversas y múltiples víctimas de gravísimas violaciones a los derechos humanos, como en los casos históricos como son, 
entre otros, el Caracazo, la Masacre del Retén de Catia y la Masacre de El Amparo, las desapariciones forzadas de Vargas, así como en los casos de los periodistas agredidos y los jueces removidos arbitrariamente; así mismo a las personas privadas de libertad en 9 establecimientos penitenciarios. Más aún, el Sistema Interamericano de Derechos Humanos, en la actualidad, también se ha configurado como uno de los métodos de mayor importancia para la tutela de derechos humanos de las personas en Venezuela, siendo que para la fecha (2012) la Corte IDH ha decidido mediante sentencias $15 \operatorname{casos}^{74}$,

74 1.- Caso El Amparo vs. Venezuela. Fondo. Sentencia 18 de enero de 1995 Serie C No 19. Violación de los Derechos consagrados en los artículos: 2 (Deber de Adoptar Disposiciones de Derecho Interno), 4 (Derecho a la Vida), 5 (Derecho a la Integridad Personal), 8.1 (Garantías Judiciales), 24 (Igualdad ante la Ley) y 25 (Protección Judicial); 2.- Caso el Caracazo vs. Venezuela. Fondo. Sentencia 11 de noviembre de 1999 Serie C No 58. Violación de los Derechos consagrados en los artículos: 4.1 (Derecho a la Vida), 5 (Derecho a la Integridad Personal), 7 (Derecho a la Libertad Personal), 8.1 (Garantías Judiciales), 25.1 y 25.2.a. (Protección Judicial) y 27.3 (Suspensión de Garantías) en concordancia con los artículos 1.1 (Obligación de Respetar los Derechos) y 2 (Deber de Adoptar Disposiciones de Derecho Interno), de la Convención Americana; 3.- Caso Blanco Romero y otros vs. Venezuela. Fondo, Reparaciones y Costas. Sentencia 28 de noviembre del 2005 Serie C No 138. Violación de los Derechos consagrados en los artículos: 4.1 (Derecho a la Vida); 5.1 y 5.2 (Derecho a la Integridad Personal); 7.1, 7.2, 7.3 , 7.4, 7.5 y 7.6 (Derecho a la Libertad Personal); 8.1 (Garantías Judiciales) y 25 (Protección Judicial); 4.- Caso Montero Araguren y otros (Retén en Catia) vs. Venezuela. Excepción preliminar, Fondo, Reparaciones, Costas. Sentencia 5 de junio del 2006 Serie C No 150. Violación de los Derechos consagrados en los artículos: 4 (Derecho a la Vida), 5 (Derecho a la Integridad Personal), 8 (Garantías Judiciales) y 25 (Protección Judicial); 5.- Caso Apitz Barbera y otros (Corte 1era de lo Contencioso Administrativo) vs. Venezuela. Excepción preliminar, Fondo, Reparaciones, Costas. Sentencia 5 de agosto del 2008 Serie C No 182. Violación de los Derechos consagrados en los artículos: 8 (Garantías Judiciales) y 25 (Protección Judicial); 6.- Caso Ríos y otros vs. Venezuela. Excepción preliminar, Fondo, Reparaciones, y Costas. Sentencia 28 de enero del 2009 Serie C No 194. Violación de los Derechos consagrados en los artículos: 5 (Derecho a la Integridad Personal), 13 (Libertad de Pensamiento y Expresión), 8 (Garantías Judiciales) y 25 (Protección Judicial); 7.- Caso Perozo y Otros vs. Venezuela. Excepción preliminar, Fondo, Reparaciones, Costas. Sentencia 28 de enero del 2009 Serie C No 195. Violación de los Derechos consagrados en los artículos: 5 (Derecho a la Integridad Personal), 8 (Garantías Judiciales), 13 (Libertad de Pensamiento y Expresión) y 25 (Protección Judicial); 8.- Caso Reverón Trujillo vs. Venezuela. Excepción preliminar, Fondo, Reparaciones, Costas. Sentencia 30 de junio del 2009 Serie C No 197. Violación del Derecho consagrado en el artículos: 25 (Protección Judicial) de la Convención, en relación con las obligaciones establecidas en los artículos 1.1 (Obligación de Respetar los Derechos) y 2 (Deber de Adoptar Disposiciones de Derecho Interno); 9.- Caso Barreto Leiva vs. Venezuela. Fondo, Reparaciones, Costas. Sentencia 17 de noviembre del 2009 Serie C No 206. Violación de los Derechos consagrados en los artículos: 7.1, 7.3 y 7.5 (Libertad Personal), 8.1, 8.2.b, 8.2.c, 8.2.d, 8.2.f y 8.2.h (Garantías Judiciales) y 25.1 (Protección Judicial); 10.- Caso Usón Ramírez vs. Venezuela. Excepción preliminar, Fondo, Reparaciones, Costas. Sentencia 20 de noviembre de 2009 Serie C No 207. Violación de los Derechos consagrados en los artículos: 13 (Libertad de Pensamiento y de Expresión), 7 (Derecho a la Libertad Personal), 8 (Garantías Judiciales) y 25 (Protección Judicial); 11.- Caso Chocrón Chocrón vs. Venezuela. Excepción preliminar, Fondo, 


\section{tenía bajo trámite 3 más ${ }^{75}$ y medidas provisionales en aproximadamente 21 asuntos ${ }^{76}$, brindándoles una tutela judicial internacional a las víctimas de los mismos.}

Reparaciones, Costas. Sentencia 1 de Julio del 2011 Serie C No 227. Violación de los Derechos consagrados en los artículos: 8 (Garantías Judiciales), 25 (Protección Judicial) y 23.1.c (Derechos Políticos); 12.- Caso López Mendoza vs. Venezuela. Fondo, Reparaciones, Costas. Sentencia 1 de septiembre del 2011 Serie C No 233. Violación de los Derechos consagrados en los artículos: artículos 23 (Derechos Políticos), 8.1 (Garantías Judiciales) y 25 (Protección Judicial), conjuntamente con los artículos 1.1 (Obligación de Respetar los Derechos) y 2 (Deber de Adoptar Disposiciones de Derecho Interno); 13.- Caso Familia Barrios vs. Venezuela. Fondo, Reparaciones, Costas. Sentencia 24 de noviembre del 2011 Serie C No 237. Violación de los Derechos consagrados en los artículos: 4 (Derecho a la vida), 5 (Derecho a la Integridad Personal), 7 (Derecho a la Libertad Personal), 8 (Garantías Judiciales), 11 (Protección de la Honra y Dignidad), 19 (Derechos del Niño), 21 (Derecho a la Propiedad), 22 (Derecho de Circulación y Residencia), y 25 (Protección Judicial); 14.- Caso Díaz Peña vs. Venezuela. Excepción preliminar, Fondo, Reparaciones, Costas. Sentencia 26 de junio del 2012 Serie C No 24. Violación de los Derechos consagrados en los artículos: 7.1, 7.2 y 7.4 (derechos a no ser privado de la libertad ilegalmente y a conocer los motivos de la detención), 7.1 y 7.3 (derecho a no ser privado de libertad arbitrariamente), 7.5 y 8.2 (derechos a ser juzgado en un plazo razonable o a ser puesto en libertad y a la presunción de inocencia), 7.6 y 25.1 (derechos a recurrir ante juez o tribunal competente para que decida sobre la legalidad de la detención y a la protección judicial), 8.1 (derecho a ser juzgado en un plazo razonable por un juez o tribunal independiente e imparcial) y 5.1 y 5.2 (derecho a la integridad personal); y 15.- Caso Uzcategui y otros vs. Venezuela. Fondo y Reparaciones. Sentencia de 3 de septiembre de 2012 Serie C No 249. Violación de los derechos consagrados en los artículos: 4.1 (Derecho a la vida), 5.1 (Derecho a la Integridad Personal), 7.1, 7.2 y 7.4 (Derecho a la Libertad Personal), 8.1 (Garantías Judiciales), 11.2 (Derecho a la vida privada), 13 (Libertad de Pensamiento y de Expresión), 19 (Derechos del Niño), 21 (Derecho a la Propiedad), y 25.1 (Protección Judicial).

75 1.- Caso José Luis Castillo González. 22 de Febrero del 2011. Caso 12.605; 2.- Caso Allan Brewer Carías. 7 de marzo del 2012. Caso 12.724; y 3.- Caso Hermanos Landaeta Mejías y otros. 10 de julio del 2012. Caso 12.606.

76 1.- Asunto Belfort Istúriz y otros respecto Venezuela (15-04-10); 2.- Asunto Carlos Nieto y otros respecto Venezuela (26-01-09, 05-08-08, 03-07-07, 22-09-06 y 09-07-04); 3.- Asunto Centro Penitenciario de Aragua "Cárcel de Tocorón” respecto Venezuela (06-07-11, 15-05-11, 24-11-10 y 01-11-10); 4.- Asunto Centro Penitenciario de la Región Andina respecto Venezuela (06-09-12); 5.- Asunto Centro Penitenciario de la Región Centro Occidental: Cárcel de Uribana respecto Venezuela (06-09-12, 07-08-12, 06-07-11, 24-11-09, 12-08-09 y 02-02-07); 6.- Asunto de la Emisora de Televisión “Globovisión” respecto Venezuela (29-01-08, 21-12-07, 21-11-07 y 04-09-04); 6.- Caso del Caracazo respecto Venezuela (28-05-10); 7.Asunto del Centro Penitenciario Región Capital Yare I y Yare II respecto Venezuela (06-09-12, 07-08-12, 06-07-11, 24-11-09, 12-08-09, 30-11-07 y 30-03-06); 8.- Asunto del Internado Judicial Capital El Rodeo I y El Rodeo II respecto Venezuela (06-09-12, 06-09-12, 07-08-12, 06-07-11, 24-11-09, 12-08-09 y 08-02-08); 9.- Asunto del Internado Judicial de Monagas ("La Pica") respecto Venezuela (06-09-12, 07-08-12, 06-07-11, 24-11-09, 12-08-09, 03-07-07 y 09-02-06); 10.- Asunto Diarios "El Nacional" y "Asi es la Noticia" respecto Venezuela (25-11-08 y 06-07-04); 11.- Asunto Eloisa Barrios y otros respecto Venezuela (05-07-11, 21-02-11, 25-11-10, 04-02-10, 18-12-09 y 22-09-05); 12.- Caso Guerrero Gallucci y Martinez Barrios respecto Venezuela (21-11-11, 29-11-07 y 04-07-06); 13.- Asunto Guerrero Larez respecto Venezuela (15-05-11 y 17-11-09); 14.- Asunto Internado Judicial de Ciudad Bolivar 
La denuncia de la CADH despoja a todas las personas, de forma inconstitucional y en los términos su artículo 78, del derecho a la protección judicial internacional ante la Corte IDH, removiendo respecto a los hechos posteriores a aquélla, la potestad jurisdiccional de dicha Corte en casos relacionados a Venezuela, y por lo tanto, excluyéndolas del derecho a acudir a los órganos jurisdiccionales internacionales, lo cual configura una evidente regresividad al además debilitar los mecanismos propios para la protección internacional de los derechos humanos.

En el presente caso, la regresividad, además, no sólo afecta al derecho de petición internacional, sino también viola de de manera evidente el artículo 339 constitucional, que expresamente reconoce una obligación de cumplir y por tanto de mantenerse vinculado con los estándares y controles internacionales previstos en la CADH en materia de estados de excepción. En efecto, esta norma constitucional, al referirse al decreto de estado de excepción, exige que éste "cumplirá con las exigencias, principios y garantías establecidos en el Pacto Internacional de Derechos Civiles y Políticos y en la Convención Americana sobre Derechos Humanos". (Textos cursivos añadidos). Por lo tanto, excluir a la CADH y por tanto las obligaciones de control internacional que se derivan de ella en materia de estados de excepción ${ }^{77}$, es relajar y disminuir los estándares de protección de

\footnotetext{
"Cárcel de Vista Hermosa" respecto Venezuela (06-07-11 y 15-05-11); 15.- Asunto Liliana Ortega y otras, respecto Venezuela (09-07-09, 14-06-05, 01-03-05, 04-05-04, 02-12-03, 21-02-03 y 27-11-02); 16.- Asunto Luis Uzcátegui respecto Venezuela (27-01-09, 04-05-04, 02-12-03, 20-02-03 y 27-11-02); 17.- Asunto Luisiana Ríos y otros, respecto Venezuela (03-07-07, 14-06-07, 12-09-05, 08-09-04, 04-0504, 02-12-03, 21-11-03, 02-10-03, 20-02-03 y 27-11-02); 18.- Asunto María Lourdes Afiuni respecto Venezuela (02-03-11 y 10-12-10); 19.- Asunto Marta Colomina y Liliana Velásquez respecto Venezuela (04-07-06, 04-05-04, 02-12-03, 08-09-03 y 30-07-03); y 20.- Asunto Natera Balboa respecto Venezuela (15-05-11, 01-02-10 y 01-12-09).

${ }_{77}$ Con relación con con las exigencias, principios y garantías y a los controles internacionales que impone la CADH en materia de estados de excepción, su artículo 27 dispone:

Artículo 27. Suspensión de Garantías

1. En caso de guerra, de peligro público o de otra emergencia que amenace la independencia o seguridad del Estado parte, éste podrá adoptar disposiciones que, en la medida y por el tiempo estrictamente limitados a las exigencias de la situación, suspendan las obligaciones contraídas en virtud de esta Convención, siempre que tales disposiciones no sean incompatibles con las demás obligaciones que les impone el derecho internacional y no entrañen discriminación alguna fundada en motivos de raza, color, sexo, idioma, religión u origen social.

2. La disposición precedente no autoriza la suspensión de los derechos determinados en los siguientes artículos: 3 (Derecho al Reconocimiento de la Personalidad Jurídica); 4 (Derecho a la Vida); 5 (Derecho a la Integridad Personal); 6 (Prohibición de la Esclavitud y Servidumbre); 9 (Principio de Legalidad y de Retroactividad); 12 (Libertad de Conciencia y de Religión); 17 (Protección a la Familia); 18 (Derecho
} 
los derechos humanos bajo estas situaciones, configurando por ello una medida evidentemente regresiva.

Como consecuencia, esta regresividad ocasionada por la denuncia de la $\mathrm{CADH}$ como instrumento internacional, viola además el principio constitucional de los derechos humanos como rector de las relaciones internacionales del Estado Venezolano, conforme al cual,

Artículo 152. Las relaciones internacionales de la República responden a los fines del Estado en función del ejercicio de la soberanía y de los intereses del pueblo; ellas se rigen por los principios de independencia, igualdad entre los Estados, libre determinación y no intervención en sus asuntos internos, solución pacífica de los conflictos internacionales, cooperación, respeto a los derechos humanos y solidaridad entre los pueblos en la lucha por su emancipación y el bienestar de la humanidad. La República mantendrá la más firme y decidida defensa de estos principios y de la práctica democrática en todos los organismos e instituciones internacionales. (Textos cursivos añadidos).

La denuncia de un tratado de derechos humanos como es la CADH, y su consecuencias de desvincular al Estado Venezolano de las obligaciones sustantivas y procesales de respeto, garantía y protección de los derechos reconocidos en dicho instrumento, es evidentemente contraria al "respeto a los derechos humanos" como principio rector de sus relaciones internacionales". Pero además, la denuncia como hemos visto, ocasiona una desmejora de la protección internacional de todas las personas bajo la jurisdicción del Estado Venezolano, ante organismos e instituciones internacionales como son la CIDH y la Corte IDH.

Tratándose el sistema interamericano de protección de los derechos humanos de un mecanismo colectivo, ello es, donde todos los Estados parte de la CADH e incluso los Estados miembros de la OEA tienen, tienen un legítimo interés en la promoción y defensa de los derechos en todos los demás Estados. Ello se manifiesta entre otros en las competencias de sus órganos políticos (cfr. Asamblea General, Consejo Permanente y Consejo de Asuntos Jurídicos y Políticos)

al Nombre); 19 (Derechos del Niño); 20 (Derecho a la Nacionalidad), y 23 (Derechos Políticos), ni de las garantías judiciales indispensables para la protección de tales derechos.

3. Todo Estado parte que haga uso del derecho de suspensión deberá informar inmediatamente a los demás Estados partes en la presente Convención, por conducto del Secretario General de la Organización de los Estados Americanos, de las disposiciones cuya aplicación haya suspendido, de los motivos que hayan suscitado la suspensión y de la fecha en que haya dado por terminada tal suspensión. 
para conocer, discutir y adoptar resoluciones relativas al avance de los derechos humanos en el hemisferio, aprobar declaraciones y tratados sobre la materia, así como temas relativos a los informes de ambos órganos interamericanos de protección. Por lo cual, ciertamente la denuncia de la CADH configura igualmente una violación del principio constitucional de los derechos humanos como rector de las relaciones internacionales del Estado Venezolano y de su deber constitucional de mantener la más firme y decidida defensa de este principio en todos los organismos e instituciones internacionales.

Es por todo anterior, que la denuncia de la CADH por parte del Gobierno de Venezuela, ha generado en distintos organismos y organizaciones internacionales el rechazo y la expresión firme de la preocupación por la regresividad que ella causa a la protección de los derechos humanos. Así, una vez que el Presidente de la República Bolivariana de Venezuela anunció en una primera ocasión la denuncia a la CADH, la Alta Comisionada para las Naciones Unidas para los Derechos Humanos aseveró que, "[e]stamos preocupados por el anuncio de Venezuela de establecer un comité estatal para evaluar la posibilidad de retirarse de la Comisión Interamericana de Derechos Humanos (CIDH). Los órganos regionales de derechos humanos juegan un rol muy importante en la promoción y protección de mecanismos de derechos humanos y refuerzan los estándares y tratados universales de derechos humanos -algo que ha sido reconocido repetidamente por la Asamblea General de la ONU y el Consejo de Derechos Humanos"78.

Amnistía Internacional reaccionó a dicho anuncio a través de un comunicado público, afirmando que "[u]n retiro de Venezuela del Sistema Interamericano implicaría negar a los y las venezolanas una importante instancia de justicia, e iría claramente en contra de la propia Constitución Bolivariana de Venezuela"79.

A nivel hemisférico, la Coalición Internacional de Organizaciones por los Derechos Humanos en las Américas manifestó enérgicamente su preocupación

\footnotetext{
${ }^{78}$ Comunicado. Alta Comisionada de las Naciones Unidas para los Derecho Humanos, Derechos Humanos de la ONU expresa preocupación por el posible retiro de Venezuela de la Comisión Interamericana de Derechos Humanos. Ginebra, 4 de mayo de 2012, disponible en: http://acnudh.org/2012/05/ derechos-humanos-de-la-onu-expresa-preocupacion-por-el-posible-retiro-de-venezuela-de-la-comisioninteramericana-de-derechos-humanos/

${ }^{79}$ Amnistía Internacional, Debate en Venezuela pone en riesgo la protección de los derechos humanos. Índice AI: AMR 53/003/2012. 17 de mayo de 2012, disponible en http://www.amnesty.org/es/library/asset/ AMR53/003/2012/es/3f3dfa80-47e3-49bb-91c2-c24de92e3405/amr530032012es.pdf
} 
por la "indefensión en la que quedarán los ciudadanos que no podrán acudir a esa instancia internacional" cuando se cercenen sus derechos humanos ${ }^{80}$.

Entre las organizaciones no gubernamentales de derechos humanos venezolanas que se pronunciaron, destacan las que integran el Foro por la Vida, quienes rechazaron "contundentemente la propuesta formulada por el Presidente de la República en días pasados, de 'retirarse' de la Comisión Interamericana de Derechos Humanos", subrayando así la utilidad fundamental de este sistema para la protección de los derechos humanos de los individuos ${ }^{81}$. Igualmente, la Comisión de Derechos Humanos de la Federación de Abogados de Venezuela manifestó su preocupación al respecto, rechazando "el acto de desafío del Gobierno de la República Bolivariana de Venezuela al promover los estudios para sustraerse de la Comisión Interamericana de Derechos Humanos" y "los intentos por parte del Gobierno Venezolano en desligarse de sus obligaciones internacionales como Estado parte de la Organización de Estados Americanos (OEA), en materia de Protección y Garantía de los Derechos Humanos de las personas bajo su jurisdicción" 82 .

Igualmente, diversas víctimas de violación de los derechos humanos en Venezuela, que han acudido ante el sistema interamericano con base en la $\mathrm{CADH}$, quiénes no encontraron ni aun encuentran justicia en Venezuela manifestaron que "el Sistema Interamericano de Derechos Humanos es su último recurso" ${ }^{83}$.

\footnotetext{
${ }^{80}$ Coalición Internacional de Organizaciones por los Derechos Humanos en las Américas, Retiro de Venezuela de la Corte IDH debilitaría la protección de los Derechos Humanos de sus ciudadanos/as. 31 de julio de 2012 en: http://espaciopublico.org/index.php/noticias/1-libertad-de-expresi/2423-coalicioninternacional-de-organizaciones-por-los-derechos-humanos-en-las-americas-expresan-su-preocupacion-sobre-el-retiro-de-venezuela-de-la-corte-idh.

${ }^{81}$ Foro por la Vida, Foro por la Vida y organizaciones sociales ante la amenaza del gobierno nacional de retirarse de la CIDH. Caracas, 11 de mayo de 2012, disponible en: http://www.conflictove.org.ve/ agenda/foro-por-la-vida-y-organizaciones-sociales-ante-la-amenaza-del-gobierno-nacional-de-retirarsede-la-cidh.html

${ }^{82}$ Comisión de Derechos Humanos de la Federación de Abogados de Venezuela, Comisión de derechos humanos de la Federación de Abogados de Venezuela el retiro de Venezuela de la Comisión Interamericana de Derechos Humanos. Caracas, 02 de mayo de 2012, disponible en: http://www.derechos.org.ve/2012/05/03/ comision-de-ddhh-del-colegio-de-abogados-rechaza-retiro-de-venezuela-de-la-cidh/.

${ }^{83}$ Rueda de prensa organizada por el Foro por la Vida, coalición de organizaciones de derechos humanos venezolana, Caracas, agosto de 2012, disponibles en: http://www.youtube.com/watch?feature=player_embedded\&v=k5J_ KIj7__s\#! ; http://www.youtube.com/watch?feature=player_embedded\&v=0HVHmV9gaSI; http:// www.youtube.com/watch?feature=player_embedded $\& v=v Q X 0 W K s q 144 ;$ http://www.youtube.com/ watch?feature=player_embedded $\& v=A w 80 \mathrm{dZxu} 7 \mathrm{lw}$
} 
Además de estas organizaciones de derechos humanos, la Academia de Ciencias Políticas y Sociales de Venezuela también expresó su rechazo a la anunciada salida de la CIDH y eventual denuncia de la CADH, y al respecto afirmó a que "la salida de Venezuela de la CIDH como ha sido anunciada, o incluso la sola denuncia de la $\mathrm{CADH}$, configurarían de conformidad con la Constitución, una violación o un menoscabo a los derechos garantizados en ella, por lo cual sería un acto "nulo" 84 .

Así mismo, en el ámbito académico, el Grupo de profesores de Derecho Público de distintas universidades venezolanas, emitieron un pronunciamiento público, en el cual reclamaron la atención de las Instituciones y de la ciudadanía, con relación a la orden presidencial para que Venezuela se "retire" de la Corte IDH y eventualmente denuncie la $\mathrm{CADH}$, "en clara violación de lo previsto en los artículos 19; 23; 31 y 339 de la Constitución de la República Bolivariana de Venezuela". En su pronunciamiento público, los profesores advirtieron que " [d]e ejecutarse la mencionada denuncia, se debilitará definitivamente la obligación internacional del estado venezolano a respetar y proteger los derechos fundamentales de todos los venezolanos, como la vida, la prohibición de torturas, la libertad personal, el debido proceso, entre otros; y los funcionarios del gobierno y del resto de los poderes públicos escaparán a la jurisdicción de un tribunal internacional que ofrece a todas las personas en Venezuela, protección internacional complementaria, cuando los tribunales de Venezuela no han sido efectivos en la protección de sus DDHH"85.

Una vez que el Gobierno de Venezuela formalizó la denuncia de la $\mathrm{CADH}$, el propio Secretario General de la OEA en su comunicado de prensa anunciando que había recibido la misma en ese día 10 de septiembre de 2012, expresó que "lamenta la decisión adoptada por el gobierno de la República Bolivariana de Venezuela, de denunciar este instrumento jurídico", ya que el mismo constituye "uno de los pilares de la normativa legal que ampara la defensa de los derechos

\footnotetext{
${ }^{84}$ Academia de Ciencias Políticas y Sociales de Venezuela, Academia de Ciencias Politicas y Sociales sobre el retiro de Venezuela de la Comisión Interamericana de Derechos Humanos (CIDH). Caracas 14 de mayo de 2012, en http://acienpol.org.ve/cmacienpol/Resources/Pronunciamientos/Pronunciamiento\%20 ACADEMICA\%20retiro\%20CIDH\%20(rev).pdf.

${ }^{85}$ Profesores de Derecho en distintas universidades: La decisión presidencial de renunciar a la Convención Americana sobre Derechos Humanos disminuirá los DDHH de TODOS los venezolanos y eliminará un mecanismo de protección adicional a la Constitución. Caracas, 1 de agosto de 2012, disponible en http://acienpol.org. $\mathrm{ve} / \mathrm{cmacienpol} /$ Resources/Noticias/PRONUNCIAMIENTO\%20DE\%20LOS\%20PROFESORES\%20 DE\%20DERECHO.pdf.
} 
humanos en el continente". Por lo cual, el Secretario General al reconocer la gravedad regresiva de la denuncia presentada "manifestó su esperanza de que en el año que debe transcurrir para que dicha decisión se haga efectiva, como lo establece el Art.78, el gobierno de la República Bolivariana de Venezuela pueda reconsiderar su decisión's6.

Por su parte, la Alta Comisionada para los Derechos Humanos de las Naciones Unidas, igualmente reaccionó de inmediato ante tan grave decisión del Gobierno Venezolano y al respecto expresó su temor que con ella "una capa vital para la protección de los venezolanos -y potencialmente de otros latinoamericanos- se adelgace si el Gobierno sigue adelante con su decisión. Serán mucho más vulnerables a los abusos y habrá menos soluciones disponibles". Además subrayó que "La Corte IDH y la CIDH no solamente han tenido un impacto extraordinariamente positivo en los Derechos Humanos de la región, sino que también han servido como ejemplos pioneros para el resto del mundo de cuán eficaces pueden ser los organismos de protección de los Derechos Humanos" ${ }^{87}$.

Amnistía Internacional, también se manifestó nuevamente y expresó públicamente que "esta acción es una afrenta a las víctimas de violaciones de derechos humanos y a generaciones futuras de venezolanos y venezolanas que carecerán de la posibilidad de acceder a este órgano regional cuando no puedan hacer valer sus derechos en su país", añadiendo que, "la posibilidad de recurrir a un organismo internacional como la Corte Interamericana es un derecho que todas y todos los venezolanos han adquirido y que esta decisión volvería imposible de ejercer" 88 .

Igualmente, la Coalición Internacional de Organizaciones por los Derechos Humanos en las Américas señaló que "[e]n su documento de denuncia, Venezuela pretende desvincularse también de la supervisión de la Comisión Interamericana. Sin embargo, este organismo podrá seguir recibiendo de-

\footnotetext{
${ }^{86}$ OEA, Secretario General de la OEA comunica denuncia de la Convención Americana sobre Derechos Humanos de parte de Venezuela, Comunicado C-307/12, 10 de septiembre de 2012, disponible en: http://www.oas.org/es/centro_noticias/comunicado_prensa.asp?sCodigo=C-307/12

${ }^{87}$ EUROPA PRESS, La ONU insta a Venezuela a reconsiderar su denuncia de la Convención de DDHH, 12 de septiembre de 2012, disponible en: http://www.europapress.es/latam/venezuela/noticia-venezuelaonu-insta-venezuela-reconsiderar-denuncia-convencion-americana-ddhh-20120912073511.html

${ }^{88}$ Amnistía Internacional, La ruptura de Venezuela con la corte regional de derechos humanos es "una afrenta a las victimas", 13 de septiembre de 2012, disponible en: http://www.amnesty.org/es/news/ ruptura-venezuela-corte-regional-ddhh-afrenta-victimas-2012-09-12
} 
nuncia o analizando situaciones de derechos humanos en ese país, en virtud de su adhesión a la Carta de la OEA y a la Declaración Americana de los Derechos y Deberes del Hombre. La medida adoptada por Venezuela debilita el camino hacia la universalidad del Sistema Interamericano que trazaron los Estados de la región. El continente necesita que todos los Estados reconozcan los instrumentos interamericanos en materia de derechos humanos. La denuncia de Venezuela es un retroceso para alcanzar dicho objetivo. Por ello, solicitamos a Venezuela que revierta su decisión de denuncia la Convención Americana y reitere su compromiso con la protección de los derechos humanos de todos/as los/as venezolanos/as. Asimismo, hacemos un llamado a los demás Estados de la OEA para que exhorten a Venezuela a no privar a sus ciudadanos del acceso al más alto Tribunal del sistema regional de protección de los derechos humanos" 89 .

En evidente por tanto, que conforme ha quedado argumentado, la denuncia de la CADH conlleva una regresividad inconstitucional, al excluir y restringir las obligaciones internacionales del Estado Venezolano, de respeto, garantía y protección de los derechos reconocidas en dicho instrumento internacional, asi como particularmente el derecho de protección ante los órganos internacionales previstos en el mismo. Además de ello, dicha denuncia disminuye y restringe la esfera de garantías minimas con las que cuentan todas las personas ante un estado de excepción. Esta misma regresividad permea al resto del ordenamiento jurídico, que se podrá ver excluido de una interpretación progresiva conforme a la CADH y su jurisprudencia, en tanto que el reconocimiento, desarrollo y la protección de derechos humanos realizada por la Corte IDH se ve removida de la gama de derechos con las que cuentan las personas, en los términos antes expuestos.

Es por todo ello, que la denuncia de la $\mathrm{CADH}$ es inconstitucional, en virtud de que viola la garantía de la progresividad y no-regresividad de los derechos humanos, reconocida en el artículo 19 de la Constitución.

\section{CONCLUSIÓN Y ACCIONES}

En conclusión, la denuncia de la CADH mediante la nota oficial diplomática identificada con el número 000125 emanada del Ministro del Poder

\footnotetext{
${ }^{99}$ CEJIL, Venezuela debilita la protección de los derechos de sus ciudadanos/as al denunciar la Convención Americana sobre Derechos Humanos, 19 de septiembre de 2012, disponible en: http://cejil.org/comunicados/venezuela-debilita-la-proteccion-de-los-derechos-de-sus-ciudadanosas-al-denunciar-la-co-0
} 
Popular para las Relaciones Exteriores, Nicolás Maduro Moros, de fecha 6 de septiembre de 2012 por órdenes e instrucciones directas del Presidente de la República Bolivariana de Venezuela, Hugo Chávez Frías, presentada ante la Secretaría General de la OEA el 10 de septiembre de 2012, es inconstitucional en virtud de ser violatoria de las normas y principios constitucionales relativos a la jerarquía y supremacía constitucional de los tratados sobre derechos humanos, el derecho de petición internacional para el amparo de los derechos humanos, los requisitos y limites constitucionales de los estados de excepción, los derechos humanos como principio rector de las relaciones internacionales del Estado Venezolano y la progresividad de los derechos humanos, consagrados en los artículos 23, 333, 339, 31, 152 y 19, respectivamente, de la Constitución.

Con base en los anteriores fundamentos constitucionales, de conformidad con lo dispuesto en el artículo 336 de la Constitución, un amplio, diverso y representativo grupo de las organizaciones no gubernamentales de derechos humanos incluyendo instancias de la Iglesia (Cáritas), de víctimas de violaciones a los derechos humanos, de defensores de derechos humanos y de abogados ${ }^{90}$,

${ }^{90}$ Dichas personas son: Marino Alvarado Betancourt, en representación del "Programa Venezolano de Educación-Acción en Derechos Humanos (Provea)"; Hilda Rosa Páez, Liliana Ortega Mendoza, Aura Rosa Liscano, Yris Del Valle Medina, y Maritza Romero Castro, en representación del "Comité de Familiares de las Víctimas de los Sucesos de febrero-marzo (Cofavic)"; Carlos José Correa Barros, Director Ejecutivo de "Espacio Público; Humberto Prado, Marianela Sánchez Ortiz y Kairin Yohanet Peñaloza Cuicas, en representación de la asociación civil sin fines de lucro "Observatorio Venezolano de Prisiones"; José Gregorio Guarenas, representando los intereses de "Vicaría Episcopal de Derecho Humanos de la Arquidiócesis de Caracas"; Feliciano Reyna, representando a las Organizaciones "Acción Solidaria” y "Civilis, A.C."; Luis Francisco Cabezas, en representación de "Convite, A.C.”; María Graciela Fajardo de Ojeda, en representación de "Comité de Familiares de las Víctimas de Atropellos Policiales y Militares del Estado Anzoátegui (Cofivanz)"; Alberto Nieves, en representación de "Acción Ciudadana contra el SIDA"; Luis Manuel Aguilera, en representación de "Justicia y Paz Aragua"; Ligia Bolívar Osuna, directora del "Centro de Derechos Humanos de Universidad Católica Andrés Bello"; Jesús María Casal, director del "Instituto de Investigaciones Jurídicas de la Universidad Católica Andrés Bello"; Raúl Arturo Herrera León, del "Centro para la Paz y los Derechos Humanos de la Universidad Central de Venezuela"; Isolda Heredia de Salvatierra, del "Observatorio Venezolano de los Derechos Humanos de la Mujer"; Monseñor Roberto Luckert León, Presidente de la "Comisión de Justicia y Paz de la Conferencia Episcopal Venezolana”; María Da Silva Dos Santos y William Jiménez Gaviria, de la "Comisión de Derechos Humanos del Colegio de Abogados de Caracas"; Natassja Palmiomiotto, Ely Rafael Tovar Flores, e Irina De la Chiquinquira Prieto, de la "Comisión de Derechos Humanos del Colegio de Abogados de Carabobo"; Eduin Aranda Moyura, de la "Comisión de Derechos Humanos del Colegio de Abogados de Anzoátegui"; Damarys Milagros Rangel matute, de la "Comisión de Derechos Humanos del Colegio de Abogados de Miranda"; Luis Manuel Guevara Prato, de la "Comisión de Derechos Humanos del Colegio de Abogados de Bolívar”; Genessis Keymart Fernández Lozada, de la "Comisión de Derechos Humanos del Colegio de Abogados de Lara"; Alejandra Josefina Iriarte De 
presentamos a la Sala Constitucional del Tribunal Supremo de Justicia el 27 de septiembre de 2012, una acción de nulidad por inconstitucionalidad contra el acto de gobierno contenido en la denuncia de la CADH. Mediante esta acción de inconstitucionalidad presentada, respetuosamente solicitamos a la Sala Constitucional que: Declare con lugar la presente acción de nulidad por razones de inconstitucionalidad, de la denuncia de la $\mathrm{CADH}$ contenido en la nota oficial diplomática identificada con el número 000125 emanada del Ministro del Poder Popular para las Relaciones Exteriores, Nicolás Maduro Moros, de fecha 6 de septiembre de 2012 por órdenes e instrucciones directas del Presidente de la República Bolivariana de Venezuela, Hugo Chávez Frías; y que en consecuencia, en ejecución de la sentencia definitiva que declare con lugar la acción de inconstitucionalidad, requiera al Ejecutivo Nacional, que en virtud del principio de colaboración de los poderes públicos establecido en el artículo 136 de la Constitución, proceda de inmediato a comunicar al Secretario General de la Organización de Estados Americanos, el retiro de la denuncia de la CADH.

Se trata de la interposición de una acción popular de inconstitucionalidad, ejercida de conformidad con lo previsto en la Ley Orgánica del Tribunal Supremo de Justicia ${ }^{91}$, dado que en Venezuela el control concentrado de la constitucionalidad sólo le corresponde a la Sala Constitucional mediante demanda popular de inconstitucionalidad. La legitimación activa en el caso de demandas de nulidad de actos de ejecución directa e inmediata de la Constitución, ello es, con rango de ley, es de naturaleza popular. En este sentido, cualquier persona natural o jurídica ostenta la legitimación activa para ejercer dicha acción. Por lo tanto, dicha Ley Orgánica del Tribunal Supremo de Justicia dispuso una legitimación popular para ejercer las acciones de inconstitucionalidad contra los actos de ejecución inmediata y directa de la Constitución.

Blanco, víctima en el caso Blanco Romero vs. Venezuela, sentenciado por la Corte Interamericana de Derechos Humanos; Inocenta Del Valle Marín, víctima en el caso Montero Aranguren y otros (retén de Catia) vs. Venezuela sentenciado por la Corte Interamericana de Derechos Humanos; Francisco Arturo Guerrero Sánchez, beneficiario de medidas provisionales dictadas por la Corte Interamericana de Derechos Humanos el 17 de noviembre de 2009; Marco Antonio Ponce, actuando en nombre propio; Pedro Nikken, Carlos Ayala Corao, Rafael Chavero, Jesús María Casal, Antonio Puppio, Francisco Alfonzo Carvallo, Oswaldo Rafael Cali Hernández y Edward Jesús Pérez, abogados defensores de derechos humanos.

${ }^{91}$ Artículo 32, Ley Orgánica del Tribunal Supremo de Justicia publicada en G.O. No 39.522 de 1 octubre de 2010 . 
Con la decisión de esta acción de inconstitucionalidad no sólo está en juego la independencia del Poder Judicial frente al Poder Ejecutivo, sino la vigencia misma de Constitución y por tanto, de la democracia, del estado de derecho y de los derechos humanos en Venezuela. 
